(02016, Elsevier. Licensed under the Creative Commons AttributionNonCommercial-NoDerivatives 4.0 International http://creativecommons.org/ about/downloads 


\title{
Agent Based-Stock Flow Consistent Macroeconomics: Towards a Benchmark Model
}

\author{
Alessandro Caiani* \\ Marche Polytechnic University \\ Mauro Gallegati \\ Marche Polytechnic University
}

\author{
Antoine Godin \\ Kingston University \\ Stephen Kinsella \\ University of Limerick
}

\author{
Eugenio Caverzasi \\ Marche Polytechnic University \\ Joseph E. Stiglitz \\ Columbia University
}

February 11, 2016

\begin{abstract}
The paper moves from a discussion of the challenges posed by the crisis to standard macroeconomics and the solutions adopted within the DSGE community. Although several recent improvements have enhanced the realism of standard models, we argue that major drawbacks still undermine their reliability. In particular, DSGE models still fail to recognize the complex adaptive nature of economic systems, and the implications of money endogeneity. The paper argues that a coherent and exhaustive representation of the inter-linkages between the real and financial sides of the economy should be a pivotal feature of every macroeconomic model and proposes a macroeconomic framework based on the combination of the Agent Based and Stock Flow Consistent approaches. The papers aims at contributing to the nascent AB-SFC literature under two fundamental respects: first, we develop a fully-decentralized AB-SFC model with several innovative features, and we thoroughly validate it in order to check whether the model is a good candidate for policy analysis applications. Results suggest that the properties of the model match many empirical regularities, ranking among the best performers in the related literature, and that these properties are robust across different parameterizations. Second, the paper has also a methodological purpose in that we try to provide a set or rules and tools to build, calibrate, validate, and display AB-SFC models.
\end{abstract}

Keywords: Agent Based Macroeconomics, Stock Flow Consistent Models, Business Cycles, Bank Regulation.

JEL Codes: E03, E32, O30

\footnotetext{
* Corresponding author: a.caiani@eco.univpm.it. This research was supported by the Institute for New Economic Thinking (INET) and the FP7 project MatheMACS. Our work has greatly benefited from comments and suggestions received from other scholars. We are grateful to the participants of the 2014 Workshop of the INET AB-SFC Macroeconomic Program at Monte Conero (Ancona, Italy). A special thanks goes to Steve Phelps for the support he gave us while developing the JMAB platform. We thank our colleagues Ermanno Catullo, Annarita Colasante, Federico Giri, Ruggero Grilli, Antonio Palestrini, Luca Riccetti, Alberto Russo, Gabriele Tedeschi, and Sean Ryan who provided insight and expertise that greatly assisted the research. Finally, we are grateful to the three anonymous referees for their valuable suggenstions that contributed to significantly improve the manuscript. All remaining errors are ours.
} 


\section{Is the economic crisis a crisis for Macroeconomics?}

More than eight years since the onset of the global financial crisis we are still assessing how the crisis should change our view about macroeconomics. The crisis cast serious doubts on the plausibility of standard macroeconomic models - in particular of dynamic stochastic general equilibrium (DSGE) models - and their ability to provide effective policy advices to prevent the occurrence of large-scale economic turmoils, and to tackle their consequences.

In a nutshell, the anatomy of the standard DSGE model presents an economy composed of different types of representative agents, such as households and firms, maximizing in a infinite lifetime horizon an objective function subject to an inter-temporal budget constraint. The first order conditions yield a fully state-contingent plan for the representative agents choice variables (e.g consumption/saving and hours dedicated to work/leisure for the consumer) looking forward from the planning date into the foreseeable future, depending on agents' expectations. Rational expectations are assumed, implying that representative agents know the "true model" of the economy, thereby having an optimal plan in response to exogenous shocks that may buffet the economy. ${ }^{1}$

To reduce the computational burden, models are usually solved using log-linearization, allowing to approximate a system of nonlinear equations into a system which is linear in terms of the log-deviations from steady state values of the associated variables (see Zietz, 2008).

One of the strongest criticisms risen against this framework in the aftermath of the crisis was centered on its alleged inability to deal with non-linearities characterizing real world behaviors and economic dynamics. In particular, the common practice of using log-linearization around the steady state forcibly imposed a stability condition on the system which eliminates the possibility of multiple equilibria, sudden state transitions, and tipping-point phenomena (Rubio-Ramirez and Fernandez-Villaverde, 2004). ${ }^{2}$ Furthermore, since the quality of the log-linearized approximation deteriorates as we move away from the steady state (Amisano and Tristani, 2007; Brunnermeier and Sannikov, 2014), this hinders its efficacy in assessing the consequences of big shocks.

In response to these limitations, several DSGE models started to incorporate different types of nonlinearities in their models, while an increasing number of contributors has adopted non-linear solution methods (see Borogan Aruoba et al. (2006) for a review of these methods): non-gaussian shocks (Andreasen et al., 2013), "smooth" non-linearities (Borogan Aruoba et al., 2013) based on curved and asymmetric decision rules, and "piecewise" non-linearities arising from kinks in decision rules (e.g. zero lower bound on nominal interest rates) are some of the expedient adopted in the recent literature. However, efforts to take the lesson of the crisis on board have mainly gone in the direction of including in the models a financial sector and "financial frictions" Brunnermeier et al. (2012) in the wake of the seminal contributions of Bernanke and Gertler (1989) and Kiyotaki and Moore (1997). Formally, financial frictions emerge when trade in certain assets cannot take place because markets are incomplete. This may happen because there is no market at all for certain state-contingent assets, or because parties are not willing to engage in certain contracts because of agency problems, arising from limited enforcement power or information asymmetries (Quadrini, 2011). In both cases, agents are unable to anticipate/postpone spending (for consumption or investment), or insure against uncertain events (to smooth consumption or investment), thus being unable to enforce their optimal state-contingent plan.

The bulk of DSGE models dealing with financial frictions typically focus on some credit constraint, limiting the amount of debt financing on the base of borrowers' collateral value, or equity constraint (Brunnermeier and Sannikov, 2014).Financial frictions can limit the flow of funds among agents, in particular towards productive "expert" agents who must borrow to pursue their investment plans. An initial small shock to expert agents' net worth can be amplified through endogenous feed-backs if productive agents are forced to fire-sell their capital thus triggering a vicious loop between drops in assets prices and drops in collateral value, which feed instability.

There is no doubt that modern DSGE models are far more complex that usually thought and that the literature on financial frictions has greatly improved their ability to mimic non-linearities and to account for episodes of financial fragility. Nonetheless, we feel that this stream of literature is still affected by major drawbacks which, if not sufficient to argue in favor of a complete demise of DSGE models, justify

\footnotetext{
${ }^{1}$ Although this framework was common to both RBC and New Keynesian DSGE models, the latter diverge in admitting that prices may not immediately adjust to clear the market, due to market imperfections (i.e. prices rigidities and monopolistic competition) and information asymmetries, possibly leading to market failures and sub-optimal social configurations.

${ }^{2}$ Indeed, a by-product of the log-linearization approximation of a DSGE model is that, whenever a shock hit with an additive random disturbance, the system behaves in either a strong stabilizing manner or in a totally explosive way. The common practice then suggested to simply rule out the unstable paths from the linearized model.
} 
the quest for alternative approaches to macroeconomic modeling.

On the one hand, the new remedies do not solve, nor address, many of the old pathologies plaguing the DSGE literature: the "olympic rationality" assumption underlying rational expectations; the reduction of agent' behaviors' to a problem of inter-temporal optimization based on technology and idle homothetic preferences (Simon, 1976); the flaws in the empirical and theoretical definition of the CES utility function and the Cobb-Douglas production function (Shaikh, 1974); the restrictive hypothesis applied to preferences and technology in order to find an internal solution to the agents' optimization problem. These are some of the unresolved issues undermining the very foundation of DSGE models. All in all, the representative agent approach at the base of DSGE models is still inherently affected by the "fallacy of composition" in taking that what is true for individual agents must also be valid for the whole economic system (Delli Gatti et al., 2010a).

Even apart from these criticisms, there is another fundamental reason to depart from the DSGE literature: though being now able to mimic non-linear dynamics, DSGE models still rely on external shocks to explain the origin of those non-linearities. Admittedly, financial frictions DSGE models still fail to understand the inherent nature of finance and money (Werner, 2014, 2015). Most of these models either assume that banks are totally absent and all lending is direct, or adopt the loanable funds approach which reduces the role of financial institutions to mere intermediaries, accepting deposits of pre-existing real resources from savers and lending them to borrowers. In reality banks do not intermediate, but rather create additional means of payment ex-novo by granting loans to non-bank customers. Every new loan recorded on the asset side of the bank's balance sheet is immediately offset by a matching liability in the form of a new deposit, so that the loan creation process corresponds to an expansion of the bank's balance sheet.

Important consequences derive from this economic fact. First, since financing allows investment projects to be carried out, the national account identity between investment and savings implies that lending is a pre-condition for savings, rather than a consequence. Second, as long as banks are free to create claims which are universally accepted as means of payment, their credit creation potential does not find any upper bound in the amount of savings available in the economy. In financial frictions DSGEs, the monetary side of the economy is fully determined in the real sphere and savings need time to be accumulated through the production of additional goods. In reality, banks can create money instantaneously by expanding their balance sheet, the only limit being represented by their own assessment of the implications of new lending for their profitability and solvency. In practice, neglecting this aspect prevents to understand the causes of financial instability and induces to dramatically underestimate its consequences. ${ }^{3}$

Besides neglecting the endogenous nature of inside money, modern DSGE models are also deficient in understanding the nature and functioning of outside money. This aspect has drawn less attention also among critics of standard macroeconomics. Standard DSGE models assume that the stock of legal money circulating in the economy is either fixed and pre-existent, or postulate that the monetary authority exogenously sets the growth rate of real money balances. No explanation is given of the actual channels by which this additional money is injected into the system, and distributed across agents. In most cases it is simply assumed that seigniorage from this activity is redistributed in a lump sum fashion to the consumers through real money transfers.

In reality, legal money is injected into the economy through two fundamental channels. The first one is represented by cash advances granted on demand by the Central Bank to banks, at the Central Bank policy rate. Since banks' demand for cash advances is determined in relation to the stock of deposits they hold, this channel fundamentally reflects the endogenous dynamics of loans and (matching) deposits. The second channel is related to fiscal policy and arises from government's payments and transfers to the private sector. These do not only increase the deposit of the receiving agent, but also (and in equal measure) the reserves of the bank holding the deposit.

Conversely, legal money is destroyed whenever a private sector agent makes a payment to the government forcing their deposit bank to transfer a portion of her legal reserves to the government.Reserves (or legal money) must be already available when making these payments suggesting that government spending must logically come before government financing, and not the other way round as postulated by standard macroeconomics, for a similar reason to why bank lending is a pre-condition to allow private agents to hold their savings in the form of liquid assets.

This economic fact also implies an important macroeconomic identity: in a closed economy, leaving

\footnotetext{
${ }^{3}$ An eminent exceptions is Benes et al. (2014) presenting a prototype model in which endogenous money is embedded within an otherwise standard DSGE model. A comparison with similar loanable funds DSGE models shows that the latter systematically underestimate the effects of exogenous shocks on bank lending, and thereby economic activity.
} 
aside Central Bank lending in the form of cash advances, the amount of legal reserves and paper money held in the private sector should be exactly equal to the amount of government bonds purchased by the Central Bank ${ }^{4}$. Failing to understand this point may thus lead to unreasonable and logically inconsistent conclusions, in particular when dealing with fiscal and macro-prudential policies. ${ }^{5}$

The arguments just proposed, while motivating our departure from the DSGE literature, also stresses that a proper representation of the financial system and of the process by which inside and outside money are created, injected, and destroyed should be a key ingredient of every macroeconomic model. In particular, our reasoning highlights the inter-relatedness of private and public agents' balance sheets, as decisions undertaken by individual agents always affect other agents, both directly and indirectly through a balance sheet channel. This interrelatedness in turn must be reflected in given macroeconomic accounting identities which affect the structure and outcomes of the economy. Every macroeconomic model should then in principle provide a complete and coherent accounting system, based on i)a realistic modeling of sectors' or individual agents' balance sheets (according to the degree of disaggregation adopted), and ii) a consistent tracking of the financial-real transactions undertaken by agents and of flows of real-financial stocks they subtend.

Our contribution goes in this direction by proposing a prototype model based on the combination of two modeling approaches: the Agent Based (Farmer and Foley, 2009; Esptein, 2006) approach, which conceives the economy as a complex adaptive system populated by heterogeneous locally interacting agents, and the Stock Flow Consistent framework (Godley and Lavoie, 2007), which provides a comprehensive and fully integrated representation of the real and financial sides of the economy through the adoption of rigorous accounting rules based on the quadruple entry principle developed by Copeland (1949).

In the next section we briefly discuss the literature on which our contribution builds in order to highlight the advantages and the drawbacks of the two approaches taken in isolation, and to outline the main contributions of our work. In particular, our paper has two fundamental objectives. On the one hand we provides a fully decentralized AB-SFC model in which accounting consistency is implemented at very bottom level in order to give account of structural interrelatedness of agents' balance sheet. The structure of the economy depicted (section 2) is kept simple and flexible enough to be progressively augmented under several directions (e.g. household debt, technological progress, stock markets), but general enough to be employed for policy analysis. In order to assess whether the model represents a good candidate for conducting policy analysis, the paper focuses on the model validation by comparing the properties of our artificial time series with several macroeconomic and microeconomic stylized facts found in the empirical literature (section 5).

Finally, we perform several sensitivity experiments (section 5.3) to check the robustness of the properties displayed by the model. Although this analysis is carried out by performing a parameter sweep on agents' heuristics, rather than by imposing a policy shock in the steady state as usual in the DSGE and $\mathrm{AB}$ macroeconomic literature, our results have some policy relevance confirming the topicality of the arguments in favor of a proper modeling of inside and outside money: the endogenous nature of money implies that banks, instead of being limited by the availability of real money balances mirroring real output growth (as usual in DSGE models), have huge margins of discretion in determining the amount of credit so that monetary means of payment exceeding the current value of real output is the norm, rather than a special case; as a consequence, even when real output is bounded by limited resources and fixed technical coefficients and even within the same institutional framework, changes in the risk aversion of banks may result in periods of excess credit affecting both the transition dynamics and the long term properties of the economy.

In addition to this, the paper has also a fundamental methodological purpose in that it aims at setting a set of replicable and general rules to build, calibrate, and validate (internally and externally) AB-SFC models building upon the best practices proposed in the AB and SFC literature, while discussing new recipes designed to address $\mathrm{AB}-\mathrm{SFC}$ specific issues, in particular regarding the calibration procedure.

\footnotetext{
${ }^{4}$ The reader can easily verify the validity of this claim by looking at table 1 in the appendix

${ }^{5}$ In particular, this rises several concerns about the implications for public debt sustainability and financial sector resilience of the claim for Central Banks independence which have become a cornerstone of neoclassical macroeconomics. These claims have gone up to the point of inhibiting Central Bank's purchases of government debt on the primary market. In our alternative perspective, government spending financed via Central Bank purchases of bonds exerts the by-product of providing safe and cheap liquid assets to financial operators, which can be used as a buffer stock to face unexpected losses during period of financial and economic instability.
} 


\subsection{An Agent Based-Stock Flow Consistent Framework}

During the seventies, Godley and Cripps (1983) and his collaborators at the Cambridge Economics Policy Group started developing their models inspired by the macro identity approaches of Kalecki, Minsky and Tobin. Their so-called "flows of funds" approach aimed at providing a comprehensive and fully integrated representation of the economy, including all financial transactions and changes in the money supply. Using flow of funds accounts to analyze the US economy at the turn of the century, Godley and Wray (1999); Godley and Zezza (2006) pointed out that growing households' indebtedness was pushing assets' inflation and leavening systemic risk under the surface of the alleged stability of the early '00s, thereby anticipating the crisis with significant precision regarding the timing and mechanics of the collapse. In 2011, the Bank of England used a flow-of-funds approach to analyze the mechanics of financial instability. Barwell and Burrows (2011) advocated the diffusion of macroeconomic approaches that stress the importance of balance sheet linkages in spotting buildups of financial fragility.

Stock Flow Consistent (SFC hereafter) models, stemming from Godley's earlier work, aim at responding to this call (Godley, 1997; Godley and Lavoie, 2007). This approach employs specific social accounting matrices to ensure that every flow of payments comes from somewhere and goes somewhere and that every financial stocks is recorded as a liability for someone and an asset for someone, so that there are no financial black holes in the model. ${ }^{6}$

This feature brings some important advantages to SFC models. First, it makes SFC models a perfectly suited tool for modeling endogenous and government money. Second, the fully integrated structure underlying the accounting matrices gives account for the interrelatedness of agents' balance sheet. Third, the logic underlying SFC models and the construction of their accounting matrix is totally coherent with the structure of national accounts. Several countries have complete flow-of-funds accounts or financial flows accounts, as well as national balance sheet accounts, thus opening the possibility of a full estimation of SFC models.

Finally and most importantly, a major advantage in employing a SFC framework is that it provides a fundamental check of the model logical consistency. As a consequence, Stock Flow Consistency should be a property of every macroeconomic model. Whenever violated, this implies that some agent or sector in the model is building a stock of financial assets or liabilities which do not find a liability or asset counterpart. These financial stocks have been originated and may give rise to transactions or financial flows which should not have occurred if the model had a consistent logic. These new flows in turn can amplify the magnitude of inconsistencies, leading to unreasonable evolutions of agents' balance sheets, and greatly undermining the reliability of model results.

Conversely, Caiani et al. (2014) and Kinsella (2011) outlined some drawbacks affecting the SFC literature. Traditional SFC models are highly aggregated, dividing the economy in major institutional sectors, typically households, banks, firms, and the public sector. ${ }^{7}$ This perspective abstracts from tracking intra-sectoral flows and does not allow to analyze the causes and effects of agents' heterogeneity emerging within and across sectors. This limit definitively hinders, and in some cases impedes, the possibility of studying phenomena which are deeply connected to agents' heterogeneity and agents' disperse interaction, such as selection and self-organization processes within markets or industries, the generation of financial bubbles, and the propagation of shocks through network-based balance sheet relationships.

In this respect, Agent Based models, geared around the conception of the economy as a complex adaptive system, may greatly help to overcome many of these limitations. Contributions in this field highlight how even the simplest microeconomic behaviors may lead to complex systemic properties due to feedbacks, externalities, and other structural effects arising from agents disperse interactions. Agent Based models have proven to be well-suited to explain the emergence of financial fragility. Much attention has been devoted to the impact exerted on business cycles by credit conditions and firms' finance, in a context of incomplete asymmetric information and imperfect financial markets (Greenwald and Stiglitz, 1993). Good examples of this field of research are Delli Gatti et al. (2005, 2008, 2010b) who focused on the role of commercial and banks' credit networks topology in spreading financial fragility through contagion effects, Cincotti et al. (2010), who investigates the link between business cycles and monetary aggregates, and Raberto et al. (2012) who focuses on regulatory capital requirement to analyze debt dynamics and business cycles.

Over recent years, several authors have advocated increasing investment in agent-based modeling in response to the crisis (Farmer and Foley, 2009; Colander et al., 2009). Empirically, agent based

\footnotetext{
6 "The fact that money stocks and flows must satisfy accounting equalities in individual budgets and in an economy as a whole provides a fundamental law of macroeconomics analogous to the principle of conservation of energy in physics." (Godley and Cripps, 1983, p.14).

${ }^{7}$ See Caverzasi and Godin (2015) for a recent survey of the SFC literature.
} 
macroeconomic models have proven to be capable of reproducing a significant number of micro and macroeconomic stylized facts (see, for example, Dosi et al., 2010, 2013, 2015; Delli Gatti et al., 2008; Assenza et al., 2015; Riccetti et al., 2014), often outperforming DSGE models (Fagiolo and Roventini, 2012). Our feeling is that AB models may greatly benefit from an integration with the SFC accounting framework having the potential to set an alternative paradigm to economic modeling, as advocated by Farmer and Foley (2009); Delli Gatti et al. (2010a).

A trivial reason to argue in favor of an $\mathrm{SFC}$ implementation of $\mathrm{AB}$ models is that most $\mathrm{AB}$ models, not dissimilarly from standard models, are not SFC. An example of inconsistency is represented by the exitentry process of firms, where it is usually assumed that new firms enter the market to replace defaulted ones with a given stock of capital and liquid assets. The question then arises of where does this additional capital come from and whom is providing this additional liquidity. Since these stocks seem to appear ex-nihilo rather than be realized through a transfer of resources, this assumption is implicitly imposing an exogenous positive shock on the model dynamics which counteracts the negative endogenous shock related to the firm's default. Not less important, while the creation of additional capital does not affect the balance sheet of other agents (since there is no liability holder for real assets), the newly created deposits should be recorded as a new liability for banks which is not matched by an inflow of other financial assets (such as reserves, as it would be if the deposits of the new firm were obtained from a transfer of liquid resources by some other agent), thereby imposing an unjustified additional negative shock on their balance sheet. This implies that the aggregate balance sheet and transaction flow matrices of the economy no longer satisfy the quadruple-entry principle. Apart from the accounting inconsistency, this fact is likely to affect the patterns of consumption, investment, savings, credit, and other macroeconomic variables in an extent difficult to evaluate: banks holding new deposits may be forced to ask more cash advances to the Central Bank in order to restore mandatory liquidity ratios, newly created deposits will be used for paying wages and to fund investment, while bringing a flow of interests to the new firm; conversely, deposits that should have been transferred by some incumbent agents to fund the creation of the new firm remain at their disposal, and can be used to determine and fund expenses for consumption and investment. Agents will pay taxes on the income and profits generated by these expenses. Small accounting inconsistencies so tend to build up over the simulation, rather than being absorbed, leading to logically incoherent flows and stocks evolutions.

Most of these inconsistencies derive from a flaw definition of the exchange of financial stocks underlying each transaction. For example, it is not unusual to find that firms' demand for external funds is determined as a residual between planned expenses (e.g. wages, interests, investment) and the firm's net-worth. In some other cases, banks are assumed to buy government bonds using their net-worth, or some related measure. In both examples, the fact that an agent have positive, possibly high, net-worth does not imply in any way that he will also have the liquid assets required to clear the transaction. A firm for example may have a great stock of real capital while having low deposits. Similarly banks may have high loans while having low reserves.

These examples allow us to rise a fundamental point motivating our contribution: although there is no doubt that empirical validation of the model properties should be a necessary condition, this is not sufficient per se. Checking the logical and accounting consistency of the structure generating those properties should be as well a crucial component of the overall model validation process. For this sake, every model should provide a clear-cut description of the financial assets involved in every type of transaction taking place in the simulated economy.

Our contribution hence distinguishes itself from other papers in the related literature under several respects. First, although $\mathrm{AB}$ modelers has recently started to move towards fully consistent models and a few attempts to develop AB-SFC models now exist in the literature (Kinsella et al., 2011; Riccetti et al., 2014; Seppecher, 2012), these contributions are highly heterogeneous both in terms of the economic issues addressed and of the solutions adopted to implement stock flow consistency. This restricts the replicability of these solutions and makes it difficult to compare them and to assess the actual consistency of the models. The diffusion of the nascent AB-SFC literature is currently hampered by the lack of a well-defined set of concepts, rules and tools to develop and validate these models. Our paper thus aims at giving a contribution in this direction by outlining what should be the key ingredients of an AB-SFC paper, and by proposing some solutions to specific challenges posed by the methodology, in particular regarding the calibration and accounting validation of these models.

Second and related to this, the paper implements an AB-SFC model from the very bottom layer, that is starting from an explicit representation of individual agents' balance sheets and decentralized transactions. To our knowledge, the economic literature provides just one other example of AB model sharing this feature: the EURACE model (see Deissenberg et al., 2008; Cincotti et al., 2010; Raberto 
et al., 2012; Dawid et al., 2012, 2014; van der Hoog and Dawid, 2015), a massively large-scale economic model of the EU economy first developed in 2006 and now implementing many hyper-realistic features such as day-by-day interactions, geographical space, and a huge variety of agents, including international statistical offices. Although our work shows several points of convergence with the philosophy of the EURACE project, our objective is different and somehow complementary.

Despite the success of EURACE as a tool for policymakers, its complexity limits by a significant degree the accessibility and re-usability by other scholars making difficult for the general audience of economists to enter the logic of the model, let alone master the skill required to manage it, and adapt it for new purposes. Furthermore, running such a large model necessitates the use of massively parallel computing clusters, which are not generally available to all scholars. Our objective differs in that we do not want to move towards a one-to-one matching of real economies, but rather we aim to develop a relatively simple and flexible AB-SFC model which can be easily employed, adapted, and changed, thus serving as a benchmark for other scholars who want to get involved in this approach.

Third, while the model can be replicated in different programming languages, its original implementation was realized using our brand new Java Macro Agent Based (JMAB) programming tool suite, explicitly designed for AB-SFC models. The platform exploits the logic of the object-oriented programming paradigm to provide a flexible and highly modular computational framework embedding general procedures to ensure and check the model stock-flow consistency at the macro, meso and micro levels. It has the potential to implement a wide variety of models and a number of crucial features of modern economic systems, in particular regarding the handling of heterogeneous real and financial stocks in agents' balance sheets (see for example section 3.2) and the representation of commercial and financial networks. The platform has been released under Beta-version and it is freely available on-line with introductive documentations explaining its structure and giving an overview of its main classes. ${ }^{8}$

Fourth, the validation of the model (section 5) has been subdivided into two components, in line with the arguments proposed: accounting validation, in which we propose two intuitive methods to check for the effective accounting coherence of the model, based on macroeconomic identities; and empirical validation in which we combine the best-practices available in the literature focusing on the model ability to replicate relevant macro and micro stylized facts emerging from the empirical literature.

Fifth, the paper proposes an innovative method to solve the problem of calibrating initial values of stocks and flows in an SFC manner (section 4), as well as several other parameters of the model. Calibration is widely recognized as one of the most tricky stages of simulation-based approaches to macroeconomics. Surprisingly, while very sophisticated techniques have been proposed for the calibration of behavioral parameters, the literature has paid almost no attention to the task of calibrating initial stock and flow values. Admittedly, almost no AB macroeconomic model provides a detailed discussion of the logic followed to determine initial values of stocks and flows. In the AB-SFC approach, this task is made even more difficult by the fact that, in order to avoid to prejudice the model with the types of logical bias discussed above, the values of stocks and flows should be compatible since the beginning. Furthermore, as the model is conceived as an approximation of reality, the relative sizes of these stocks should be set at reasonable levels. Given that AB models usually require a 'burn-in' period, agents should be endowed with sufficiently high buffer stocks (e.g. capital, deposits, reserves) to face possible strange or extreme dynamics originated in this phase, possibly inducing the economy to snawball. Achieving these three results together is not trivial. In particular, since models usually do not have the variety of real and financial stocks observed in reality, the need to accomplish mutual coherence between stocks values significantly circumscribes the leeway to achieve the other two conditions. In an $\mathrm{AB}$ perspective, calibration should also specify how these values are distributed among agents, and then, how the age, time to maturity, original and outstanding values of each specific stock in the balance sheet of agents is determined. Finally, calibration shall also define how the balance sheets of agents are initially connected, that is for each financial asset held by an agent (e.g. a loan for a bank) we have to identify who is the liability counterpart (the borrower for that specific loan).

The last two aspects of the calibration procedure are also connected to a sixth aspect which distinguishes our model from other contribution in the literature. Most macroeconomic AB models (Delli Gatti et al. (2010a); Riccetti et al. (2013, 2014); Dosi et al. (2012) and later works with the Schumpeter+Keynes model) still assume that loans are granted at the beginning of the period and repaid at the end of the period. This hypothesis prevents to grasp the inherent discrepancy between the short-termism of banks liabilities (i.e. demand deposits) and the typical long-termism of banks' assets (i.e. loans) whose relevance dramatically emerges during credit crisis. Most of the credit risk that lenders bear originates from this temporal dimension of credit. Our model instead assume that loans have a duration of 20 periods

\footnotetext{
${ }^{8}$ The platform, the installation guide, and related documentation can be found at: https://github.com/S120/jmab.
} 
and are progressively repaid following a constant-share amortization schedule. In addition, the model features multiple banks and allows firms to fall into debt with different banks through endogenous credit market interactions, rather than imposing a single loan with a single bank (as for example in Riccetti et al. (2014); Delli Gatti et al. (2010a); Dosi et al. (2012) or multiple loans with a single 'giant' bank (as in Assenza et al. $(2015))^{9}$. Besides allowing the model to replicate several stylized facts related to the distribution of credit between firms and banks (see section 5), there are other good theoretical reasons for having multiple banks, as banks' flexibility in creating money through loans should be limited by the need to remain profitable in a competitive banking system. ${ }^{10}$

In addition, the model presents a fully disaggregated-fully decentralized economy in which all transactions between private agents occur through local interactions based on matching protocols, rather than aggregating some sector (as for example in Seppecher, 2012; Assenza et al., 2015), or assuming replicator equations as usual in the evolutionary literature (see for example [and later works] Saviotti and Pyka (2004); Verspagen (2002); Dosi et al. (2010)). This allows not only to analyze the microeconomic distributions of several important variables, but to generate them as an emergent properties of agents' disperse interaction rather than the reflection of a behavioral assumption.

Finally, the model also presents several aspects on novelty in the definition of agents' heuristics, in particular related to firms' investment and funding behavior, banks' interest and lending (and rationing) strategies, and the management of firms' and banks bankruptcies. To avoid repetitions, we postpone the discussion of these aspects to the dedicated sections.

\section{The model}

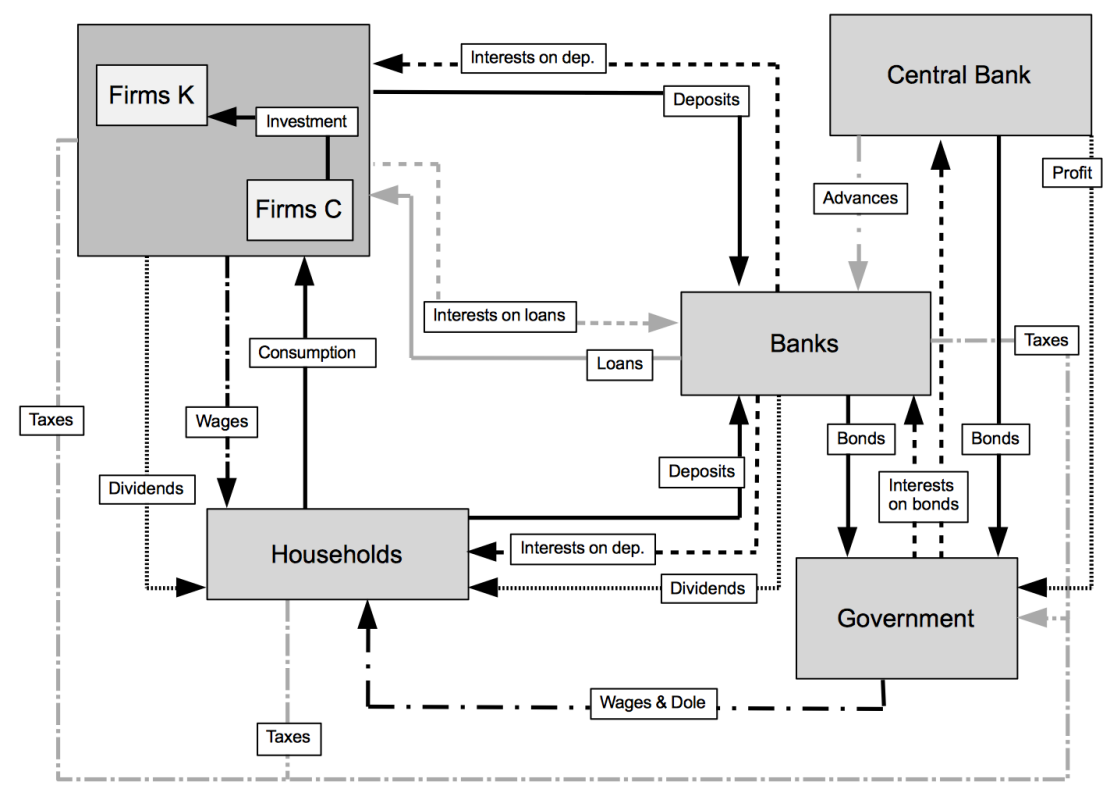

Figure 1: Flow Diagram of the model. Arrows point from paying sectors to receiving sectors.

The economy described by the flow diagram of figure 1 is composed of:

- A collection $\Phi_{H}$ of households selling their labor to firms in exchange for wages, consuming and saving in the form of banks' deposits. Households own firms and banks proportionally to their wealth, and receive a share of firms' and banks' profits as dividends. Unemployed workers receive a dole from the government. Finally, households pay taxes on their gross income.

\footnotetext{
${ }^{9}$ The main reason for these simplifying assumptions is not to be found on the theoretical level, but rather in the technical difficulties to handle the multiplicity of heterogeneous loans characterized by different age, different interest rates, different liability and asset holders, etc. JMAB effectively overcomes these difficulties by exploiting the opportunities of Object Oriented Programming.

${ }^{10}$ To our knowledge, the only model sharing these features is the Eurace/Eurace-UniBi model (Raberto et al., 2012; van der Hoog and Dawid, 2015)
} 
- Two collections of firms: consumption $\left(\Phi_{C}\right)$ and capital $\left(\Phi_{K}\right)$ firms. Consumption firms produce a homogeneous consumption good using labor and capital goods manufactured by capital firms. Capital firms produce a homogeneous capital good characterized by the binary $\left\{\mu_{k}, l_{k}\right\}$, indicating respectively the capital productivity and the capital-labor ratio. Firms may apply for loans to banks in order to finance production and investment. Retained profits are held in the form of banks' deposits.

- A collection $\Phi_{B}$ of banks, collecting deposits from households and firms, granting loans to firms, and buying bonds issued by the Government. Mandatory capital and liquidity ratios constraints apply. Banks may ask for cash advances to the Central Bank in order to restore the mandatory liquidity ratio.

- A Government sector, which hires public workers (a constant share of the workforce) and pay unemployment benefits to households. The government holds an account at the Central Bank, collects taxes, and issues bonds to cover its deficits.

- A Central Bank, which issues legal currency, holds banks' reserve accounts and the government account, accommodates banks' demand for cash advances at a fixed discount rate, and possibly buy government bonds which have not been purchased by banks.

During each period of the simulation agents interact on five markets:

- A consumption goods market: households interact with consumption firms;

- A capital goods market: consumption firms interacts with capital firms;

- A labor market: households interact with government and both types of firms;

- A credit market: firms interact with banks;

- A deposit market: households and firms interact with banks.

Following Riccetti et al. (2014), we explicitly model agents' dispersed interactions by assuming that agents on the demand and supply sides of each market interact through a common matching protocol. In each period of the simulation, 'demand' agents are allowed to observe the prices or the interest rates charged by a random subset (whose size depends on a parameter $\chi$ reflecting the degree of imperfect information). Agents' switch from the old partner to the best potential partner selected in this random subset with a probability $\operatorname{Pr}_{s}$ which is defined, following Delli Gatti et al. (2010a), as a non-linear (decreasing when the price/interest represents a disbursement for the demander, increasing otherwise) function of the percentage difference in their prices $p_{\text {old }}$ and $p_{n e w}$. The shape of this function is governed by the 'intensity of choice' parameter $\epsilon>0$ : higher values of $\epsilon>0$ imply a higher probability of switching. ${ }^{11}$

In some cases, some suppliers exhaust inventories available for sale, possibly leaving some customers with a positive residual demand. We then allow demand agents to look for other suppliers within the original random subset of potential partners in order to fulfill it. Markets interactions are 'closed' when demand agents have fulfilled their demand, when there are no supply agents willing or able to satisfy their demand, or if demanders run out of deposits to pay for demanded goods.

Agents' interactions generates several types of economic transactions and financial transfers. As argued before, a clear-cut description of the types of real and financial flows taking place in the model, is a key aspect for assessing the accounting and logical consistency of a model. Hence, we classify the flows arising in the model as follows:

Deposit transfers: If agents involved hold their deposits at the same bank, payer's deposit is decreased and receiver's increased. Otherwise, also a reserve transfer for the same amount from the payer's bank to the receiver's bank takes place. The same occurs when an agent decides to move its deposits to a new bank.

Dividends and deposits interests: Firms pay dividends through via deposit transfers. Interests on deposits are paid by simply increasing customers' deposits by the required amount. The same occurs for dividends, when the receiver holds a deposit at the paying bank. Otherwise, also a reserve transfer for the dividend amount from the paying bank to the receiver's bank takes place.

\footnotetext{
${ }^{11}$ A detailed description of all model equations can be found at: http $: / /$ papers.ssrn.com $/$ sol $3 /$ papers.cfm?abstract f $_{i}=$ 2664125
} 
Private workers' wages: wages of private workers by firms are paid via a deposit transfer, as explained above.

Public servants' wages and dole: public workers' wages and unemployment benefits give rise to the same type of transfers. The receiver's deposit is increased while reserves are subtracted to the government account at the Central Bank and transferred to the receiver's bank.

Taxes: firms' and households pay taxes using their deposits. Accordingly, the payer's bank transfers reserves for the same amount to the government account at the Central Bank. Banks pay taxes by transferring reserves to the government account at the Central Bank.

Purchase of real goods: transactions in real goods are cleared via a deposit transfer. Contextually, also real goods motivating the transaction are transferred from the seller's to the buyer's asset side.

Purchases of bonds, repayment, and interests: Bonds are a liability for the government and an asset for banks and the Central Bank. Central Bank's purchases increases its liabilities (i.e. reserves, that is legal money) while also increasing the government account at the Central Bank. Interests on bonds are immediately re-distributed to the government. Commercial banks purchases of bonds are cleared via a transfer of reserves from banks to the government current account at the Central Bank. Bonds repayments and bonds interest payments give rise to the opposite flows.

Loans creation, repayment, and interests: Loans and matching deposits are created endogenously and ex-nihilo as explained above. Interest payments and principal repayments (reducing the stock of loans) give rise to the same type of transfers. If borrower's deposit bank coincides with the lending bank, the payment is realized by lowering the borrower's deposit. If the the borrower's moved his deposits to another bank, also a corresponding reserves transfer from the borrower's bank to the lending bank takes place.

Cash advances creation, repayment, and interests: Cash advances are a loan extended by the Central Bank to commercial banks which is matched by a temporary increase of banks' reserves (a liability for the Central Bank). Conversely, cash advances repayments extinguished the loan while reducing commercial banks' reserve accordingly. Interest payments give rise to the same type of transfer, reducing private banks' reserves. Interests on cash advances are distributed to the government by increasing its deposit account at the Central Bank.

Table 2 in appendix B shows how this micro flows build up in shaping the Transaction Flow Matrix of the overall economy (data refer to the initial set-up of the simulation). The upper section of the matrix displays flows taking place during a period of the simulation, while the bottom section shows how this flows determine the variation of financial assets, thus providing a full integration between the Transaction Flow Matrix and the Balance Sheet matrix of the economy displayed in table 1. Stock Flow Consistency implies, as explained in Godley and Lavoie (2007), that the rows and columns of the Transaction Flow Matrix sum to $0 .^{12}$

\subsection{Sequence of events}

In each period of the simulation, the following sequence of events takes place:

1. Production planning: consumption and capital firms compute their desired output level.

2. Firms' labor demand: firms evaluate the number of workers needed to produce.

3. Prices, interest, and Wages: consumption and capital firms set the price of their output; banks determine the interest rate on loans and deposits. Workers adaptively revise their reservation wages.

4. Investment in capital accumulation: consumption firms' determine their desired rate of capacity growth and, as a consequence, their real demand for capital goods.

5. Capital good market (1): consumption firms choose their capital supplier.

6. Credit demand: Firms assess their demand for credit and select the lending bank.

7. Credit supply: Banks evaluate loan requests and supply credit accordingly.

8. Labor market: unemployed workers interact with firms on the labor market.

9. Production: capital and consumption firms produce their output.

10. Capital goods market (2): consumption firms purchase capital from their supplier. New machineries are employed in the production process starting from the next period.

11. Consumption goods market: households interact with consumption firms and consume.

\footnotetext{
${ }^{12}$ The table also displays two types of flows, the change in inventories nominal value and capital amortization, which are not treated above as they do not correspond to any actual exchange of real or financial resources between agents. Both however enters in the accounting definition of profits (which is employed in the determination of taxes and dividends). Notice that this implies that profits, in accordance with reality and contrary to most models where the variation of firms' deposits is assumed equal to net-profits, do not coincide with firms' operating cash flows (see section 3.1.3)
} 
12. Interest, bonds and loans repayment: firms pay interests on loans and repay a (constant) share of each loan principal. The government repays bonds and interest to bonds' holders. Banks pay interest on deposits. Cash advances and related interests, when present, are repaid.

13. Wages and dole: wages are paid. Unemployed workers receive a dole from the government.

14. Taxes: taxes on profits and income are paid to the government.

15. Dividends: dividends are distributed to households.

16. Deposit market interaction: households an firms select their deposit bank.

17. Bond purchases: banks and the Central Bank purchase newly issued bonds.

18. Cash Advances: the Central Bank accommodates cash advances requests by private banks.

In each period of the simulation, firms may default when they run out of liquidity to pay wages or to honor the debt service while banks default if their net wealth turns negative. The effects of firms' and banks' defaults are treated in section 3.3.

\section{Agent behaviors}

This section details the behavior of each type of agents. We used the following notation in the equations. Consumption firms variables have a $c$ subscript, capital firms a $k$, households a $h$ and banks a $b$. If the variable is identical for consumption and capital firms, we used the $x$ subscript. All agents share the same simple adaptive scheme to compute expectations (indicated by a $e$ superscript) for a generic variable $z$ :

$$
z_{t}^{e}=z_{t-1}^{e}+\lambda\left(z_{t-1}-z_{t-1}^{e}\right)
$$

\subsection{Firm behavior}

\subsubsection{Production planning and labor demand}

Firm $x$ desired output in period $t\left(y_{x t}^{D}\right)$ depends on the firm's sales expectations $s_{x t}^{e}$. We assume firms want to hold a certain amount of real inventories, expressed as a share $\nu$ of expected sales, as a buffer against unexpected demand swings (Steindl, 1952) and to avoid frustrating customers with supply constraints (Lavoie, 1992).

$$
y_{x t}^{D}=s_{x t}^{e}(1+\nu)-i n v_{x t-1} \text { with } x=\{c, k\}
$$

Firms in the capital-good industry produce their output out of labor only. Capital firms' demand for workers depends on $y_{k t}^{D}$ and the labor productivity $\mu_{N}$, which we assume to be constant and exogenous.

$$
N_{k t}^{D}=y_{k t}^{D} / \mu_{N}
$$

The labor requirement of any consumption firm $c$ can be calculated as:

$$
N_{c t}^{D}=u_{c t}^{D} \frac{k_{c t}}{l_{k}}
$$

where $k_{c t}$ indicates the real stock of capital, $l_{k}$ is the constant capital-labor ratio, and $u_{c t}^{D}$ is the rate of capacity utilization needed to produce the desired level of output $y_{c t}^{D}$, given by:

$$
u_{c t}^{D}=\operatorname{Min}\left(1, \frac{y_{c t}^{D}}{k_{c t} \mu_{K}}\right),
$$

where $\mu_{K}$ indicates (fixed) capital productivity.

Workers in excess, when present, are randomly sampled from the pool of firm employees and fired. We also assume a positive employee turnover, expressed as a share $\vartheta$ of firm's employees.

\subsubsection{Pricing}

Prices of goods are set as a non-negative markup $m u_{x t}$ over expected unit labor costs:

$$
p_{x t}=\left(1+m u_{x t}\right) \frac{W_{x t}^{e} N_{x t}^{D}}{y_{x t}^{D}},
$$

where $W_{x t}^{e}$ is the expected average wage. 
The mark up is endogenously revised from period to period following a simple adaptive rule. When firms end up having more inventories than desired (see section 3.1.1), the markup is lowered in the next period, in order to increase the attractiveness of their output.

$$
m u_{x t}= \begin{cases}m u_{x t-1}(1+F N) & \text { if } \frac{i n v_{x t-1}}{s_{i t-1}} \leq \nu \\ m u_{x t-1}(1-F N) & \text { if } \frac{i n v_{x t-1}}{s_{i t-1}}>\nu\end{cases}
$$

where $F N$ is a random number picked from a Folded Normal distribution with parameters $\left(\mu_{F N}, \sigma_{F N}^{2}\right)$.

\subsubsection{Firms' profits}

Consumption firms' pre-tax profits are the sum of revenues from sales, interest received, and the nominal variation of inventories, ${ }^{13}$ minus wages, interest paid on loans, and capital amortization:

$$
\begin{aligned}
& \pi_{c t}=s_{c t} p_{c t}+i_{b t-1}^{d} D_{c t-1}+\left(i n v_{c t} u c_{c t}-i n v_{c t-1} u c_{c t-1}\right) \ldots \\
& \ldots-\sum_{n \in N_{c t}} w_{n t}-\sum_{j=t-\eta}^{t-1} i_{j}^{l} L_{c j} \frac{\eta-[(t-1)-j]}{\eta}-\sum_{k \in K_{c t-1}}\left(k^{k} p^{k}\right) \frac{1}{\kappa}
\end{aligned}
$$

where $i_{b t-1}^{d}$ is the interest rate on past period deposit $D_{c t-1}$ held at bank $b, u c_{c}$ are unit costs of production, $w_{n t}$ is the wage paid to worker $n, i_{j}^{l}$ is the interest rate on loan $L_{c j}$ obtained in period $j=t-\eta, \ldots, t-1, p^{k}$ is the price paid for the batch of capital goods $k^{k}$ belonging to the firm's collection of capital goods $K_{c t-1}$, and $\eta=\kappa$ are the duration of loans and capital respectively. Capital firms' profits only differ in that they do not display capital amortization.

This accounting definition of profits is then used to compute the amount of taxes firms have to pay: $T_{x t}=\operatorname{Max}\left\{\tau_{\pi} \pi_{x t}, 0\right\}, \tau_{\pi}$ being the corporate profits tax rate. Dividends are then computed as a constant share $\rho_{x}$ of firm's after-tax profits: $\operatorname{Div} x t=\operatorname{Max}\left\{0, \rho_{x} \pi_{x t}\left(1-\tau_{\pi}\right)\right\}$.

We also consider an alternative measure of firms' performance in order to capture the actual ability of the firm to generate cash inflows through its normal business operation. We define the 'operating cash flow' $O C F_{x t}$ as after-tax profits plus capital amortization costs (for consumption firms), minus changes inventories and principal repayments.

Operating cash flow can be interpreted as a sort of 'Minskian' litmus paper: an $O C F \geq 0$ implies that the firm is capable of enough generating cash flow to honor the debt service (hedge position). If the $O C F$ is negative, but its absolute value is less than or equal to the principal repayment, the firm is in a speculative position since its cash flows are sufficient to cover the interest due, but the firm must roll over part or all of its debt. Finally, when the $O C F$ is negative and its absolute value is greater than principal payments, the firm is trapped in a Ponzi position.

\subsubsection{Investment}

Firms invest in each period in order to attain a desired productive capacity rate of growth $g_{c t}^{D}$ depending on the desired rate of capacity utilization $u_{c t}^{D}$ and the past period rate of return, defined as in equation 3.10 .

$$
\begin{aligned}
g_{c t}^{D} & =\gamma_{1} \frac{r_{c t-1}-\bar{r}}{\bar{r}}+\gamma_{2} \frac{u_{c t}^{D}-\bar{u}}{\bar{u}} \\
r_{c t} & =\frac{O C F_{c t}}{\sum_{k \in K_{c t-1}}\left(k^{k} p^{k}\right)\left(1-\frac{a g e_{k t-1}}{\kappa}\right)} .
\end{aligned}
$$

Here, $\bar{u}$ and $\bar{r}$ denote firms' 'normal' rates of capacity utilization ${ }^{14}$ and profit respectively, both assumed to be constant and equal across firms. The denominator in equation 3.10 expresses the previous period value of the firm's stock of capital, with $a g e_{k t-1}$ indicating the age in period $t-1$ of the batch of capital goods $k$ belonging to the collection $K_{c t}$ of firm $c$.

\footnotetext{
${ }^{13}$ In accordance with standard accounting rules, firms' inventories are evaluated at the firms' current unit cost of production.

${ }^{14}$ A Empirical evidence shows that firms normally display excess capacity, aiming for normal rates of utilization ranging in the 80-90\% range (Eichner, 1976). Steindl (1952) and Lavoie (1992) suggest that firms plan some excess capacity in order to avoid to constrain demand in case of large growth in demand; Spence (1977) argues that excess capacity is employed by incumbent firms as a deterrent to entry by new firms. For a detailed discussion about empirical and theoretical contributions on excess capacity see Lavoie (2015).
} 
Given $g_{c t}^{D}$, we can derive the real demand for capital goods $i_{c t}^{D}$ as the number of capital units required to replace the obsolete capital ${ }^{15}$, and to fill the gap between current and desired productive capacity level. Once firms have chosen their capital good suppliers, nominal desired investment $I_{c t}^{D}$ can be computed by multiplying $i_{c t}^{D}$ for the price $p_{k t}$ applied by the selected supplier $k$.

\subsubsection{Firms' finance}

Since Fazzari et al. (1988), more and more empirical evidence contradicting the Modigliani and Miller (1958). Solid arguments have been provided in favor of a pecking order theory of finance (Meyers, 1984): in the presence of imperfections in capital markets (e.g. information asymmetries), the cost of external finance (equity emissions and loans) is usually high. Firms then resort to external financing when internal funding possibilities have been completely exhausted. However, evidence shows that firms almost never arrive to the point of exhausting all their internal resources before asking for credit. We therefore assume that firms desire to hold a certain amount of deposits, expressed as a share $\sigma$ of the expected wages disbursement, for precautionary reasons. The demand for credit by consumption firms is then:

$$
L_{c t}^{D}=I_{c t}^{D}+D i v_{c t}^{e}+\sigma W_{c t}^{e} N_{c t}^{D}-O C F_{c t}^{e}
$$

where Div $v_{c t}^{e}$ is the expected dividends disbursement (based on expected profits). Credit demand function for capital firms can be derived from equation (3.11) by omitting $I^{D}$.

\subsubsection{Labor, Goods and Deposit markets}

After the credit market interaction between banks and firms has taken place, firms interact with unemployed households on the labor market. Production then takes place. Firms' output can be constrained by the scarcity of available workers (i.e. full employment case) or by productive capacity constraints.

Households and consumption firms then interact on the consumption good market and households consume. Consumption firms buy capital goods previously ordered (see section 3.1.4) which will be employed in next periods.

Finally, gross profits $\pi_{x t}$ are computed, taxes $T_{x t}$ are paid, and dividends $D i v_{x t}$ distributed to households (see section 3.4).

\subsection{Bank behavior}

As explained in the introduction, our model features an endogenously evolving credit network with firms interacting with several banks on the credit market during each round of the simulation, selecting the best partner and possibly obtaining multi-periodal loans. ${ }^{16}$ As a consequence, firms will generally have a collection of heterogeneous loans with different banks. Firms' possibility to obtain a loan depend on the credit rationing mechanism employed by banks to evaluate loans request. In the earliest $A B$ macroeconomic literature, banks were assumed to accommodate loan requests by borrowers, eventually discriminating borrowers only through interest rates. In reality banks mainly discriminate through credit rationing rather than interest rates (see Jakab and Kumh, 2014, for a survey of empirical literature) while the empirical evidence suggests that credit is a more important driver of real activity than the price of credit (Waters, 2013).

Recently, AB models has started to introduce some credit rationing mechanisms. Riccetti et al. (2014) assume banks sets an upper bound to loans that can be grant to single borrowers, expressed as a share of total loans. Dosi et al. (2013) assume a maximum level of credit as a multiple of deposits, badly ranked firms may thus result credit constrained if better ranked ones exhaust it. Similarly, van der Hoog and Dawid (2015) and Raberto et al. (2012) assume banks are willing to accommodates loan requests as long as their outstanding credit is compatible with capital requirements. Assenza et al. (2015) instead assume banks have a maximum admissible loss on each loan which is employed to determine an upper bound to borrowers' credit, based on their estimated probability of default.

Our contribution aims to push further this frontier by introducing a novel quantity rationing mechanism which explicitly takes into account both the risk and the expected internal rate of return associated to each credit application. A second point of departure is that, in evaluating borrowers' credit worthiness,

\footnotetext{
${ }^{15}$ For sake of realism, we assume that the financial value of each capital batch is lowered by a constant share $(1 / \kappa)$ of the original purchasing value in each period, while the correspondent real stock of machinery can be used at full potential till it reaches age $=\kappa$

${ }^{16}$ Loans last for $\eta=20$ periods (i.e. 5 years) and are repaid following the same amortization scheme: in each period firms repay a constant share $(1 / \eta)$ of the original amount.
} 
banks do not employ a stock measure, such as the leverage ratio. Instead, they look at the applicant's operating cash flows, which provides (as explained in section 3.1.3) a more effective measure of the firm's ability to generate cash inflows to honor past and future debt commitments. Banks' credit supply in the model is so based on the following three pillars:

- Active management of banks' balance sheet through endogenously evolving capital ratio targets and interest rate management strategy.

- Case-by-case quantity rationing based on applicants' probability of default and the ensuing loan project expected rate of return.

- Credit worthiness based on operating cash flows and collateral value.

Banks' interest rates on loans depend on a comparison between bank's current capital ratio $C R_{b t}=$ $N W_{b t} / L_{b t}^{T o t}$ and the common target $C R_{t}^{T},{ }^{17}$ determined for simplicity reasons as the past-period average of the sector. When banks are more capitalized than desired, they try to expand further their balance sheet by attracting more customers on the credit market, offering an interest rate lower than their competitors' average. In the opposite case firms want to reduce their exposure: a higher interest rate has the twofold effect of making bank's loans less attractive while increasing banks' margin. Formally:

$$
i_{b t}^{l}= \begin{cases}\bar{i}_{b t-1}^{l}(1+F N) & \text { if } C R_{b t}<C R_{t}^{T} \\ \bar{i}_{b t-1}^{l}(1-F N) & \text { otherwise }\end{cases}
$$

where $\bar{i}_{b t-1}^{l}=\frac{\sum_{b \in \Phi_{B}} i_{b t-1}^{l}}{\text { size }_{B}}$ is the market average interest rate in the previous period and $F N$ is a draw from a Folded Normal Distribution $\left(\mu_{F N}, \sigma_{F N}^{2}\right)$.

Case-by-case credit rationing mechanism starts with banks evaluating applicants' single-period probability of default, under the hypothesis thats the loan requested is granted. We define the debt service variable as the first tranche of payment associated to the hypothetic loan: $d s^{L^{d}}=\left(i_{b t}^{l}+\frac{1}{\eta}\right) L^{d}$. The probability of a default in each of the 20 periods ahead is then computed using a logistic function, based on the percentage difference between borrowers' $O C F_{x t}$ and $d s^{L^{d}}$ :

$$
p r_{x}^{D}=\frac{1}{1+\exp \left(\frac{O C F_{x t}-\varsigma_{x} d s^{L^{d}}}{d s^{L^{d}}}\right)},
$$

$\varsigma_{c}$ and $\varsigma_{k}$ are two parameters expressing banks' risk aversion in lending to capital and consumption firms. The higher $\varsigma$ the more banks are risk averse (i.e. the higher the probability of default for given $O C F$ and $d s)$.

The expected return of a credit project also depends on firms' collateral: consumption firms' collateral is identified with their stock of real capital. In the case of a default by a consumption firms, each bank then expects to be able to recover a share $\delta_{c}<\leq 1$ of outstanding loans to the defaulted firm $c$ through fire sales of its capital. $\delta_{c}$ is equal to ratio between firm's capital discounted value (see section 3.3) and firm's outstanding debt, for all lenders, being revenues from fire sales distributed across creditors proportionally to their exposure. $\delta_{k}=0$ since capital firms have no collateral. Knowing $L^{d}, i_{b t}^{l}, p r_{x}^{D}, \delta_{x}$, banks compute the overall expected return of a credit project by summing the payoffs arising from each possible outcome of the decision to grant the loan, each one weighted for its probability of occurrence. Figure 3.2 provides a graphical representation of the 'payoffs tree'.

Banks are willing to satisfy agents' demand for credit whenever the expected return is greater or equal than zero. Otherwise, the bank may still be willing to provide some credit, if there exist an amount $L^{D *}$ for which the expected return is non-negative.

\section{Deposits and bonds market}

Banks hold deposits of households and firms.

As banks have to satisfy mandatory liquidity ratios (8\%) and since deposits represent a source of reserves much cheaper than Central Bank cash advances (that is, $i_{b t}^{d}<<\bar{i}_{c b}^{a}$ ) banks compete with each other on the deposit market. ${ }^{18}$ As in the case of the capital ratio, we assume that banks have, besides the mandatory lower bound, a common liquidity target $L R_{t}^{T}$ defined as the sector average in the last period.

\footnotetext{
${ }^{17}$ Yet, banks' capital ratio has a mandatory lower bound $(6 \%)$.

${ }^{18}$ Whenever the liquidity ratio falls below the mandatory threshold banks apply for cash advances to the Central Bank (see 3.5).
} 


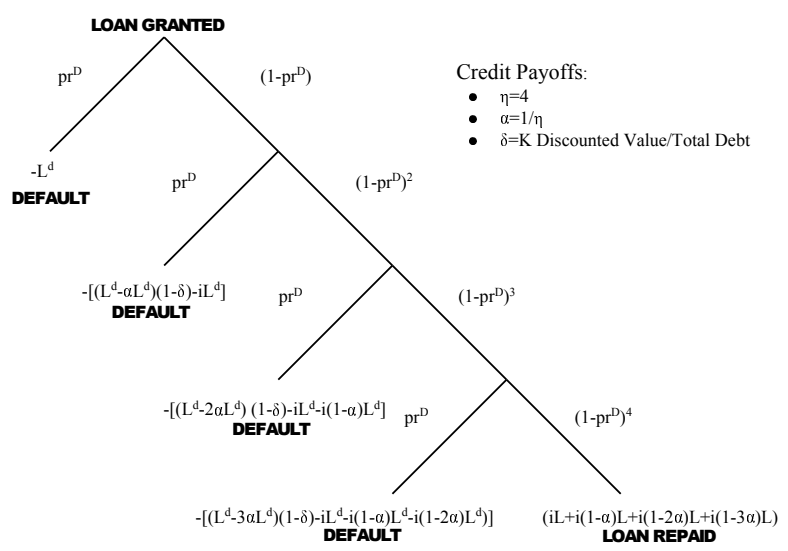

When the liquidity ratio is below the target banks set their interest on deposits as a stochastic premium over the average interest rate in order to attract customers, and vice-versa when banks have plenty of liquidity.

$$
i_{b t}^{d}= \begin{cases}\bar{i}_{b t-1}^{d}(1-F N) & \text { if } L R_{b t} \geq L R_{t}^{T} \\ \bar{i}_{b t-1}^{d}(1+F N) & \text { otherwise }\end{cases}
$$

where $F N$ being drawn from a Folded Normal Distribution $\left(\mu_{F N}, \sigma_{F N}^{2}\right)$.

Finally, we assume that banks use their reserves in excess of their target (after repayment of previous bonds by the government) to buy government bonds. Remaining bonds are assumed to be purchased by the Central Bank.

\subsection{Firms' and banks' bankruptcy}

Firms and banks may go bankrupt when they run out of liquidity or if their net-wealth turns negative. For simplicity reasons, we assume defaulted firms and banks to be bailed in by households (who are the owners of firms and banks and receive dividends) and depositors in order to maintain the number of firms and banks constant.

A bankruptcy by a firm induces non-performing loans for its creditors, who see their net wealth shrinking. In the case of capital firms, the loss is totally borne by banks, as capital firms do not have any collateral. In the case of a consumption firm, we assume that its ownership passes temporarily to creditors which try to recover part of their outstanding loans through fire sales of firm's physical capital to households.

In accordance with empirical evidence, we assume the financial value of assets sold through fire sales to be lowered by a share $\iota$. When the discounted value of capital is greater or equal to the firm's bad debt, the loss caused by the bankruptcy falls completely on households' shoulders. However, in general the loss is split between households and banks which are able to recover only a fraction of their loans. Individual households' contribution to fire sales follows the same rule of dividends distribution (section 3.4), the disbursement being distributed proportionally to households' net wealth.

Banks default when their net-worth turns negative. We assume depositors bear the loss associated to the default. In order to restore a positive net-wealth, deposits are lowered up to the point the bank's capital ratio equals the minimum capital adequacy requirement $(6 \%)$, similar to a bail-in process. The total loss borne by the depositor is distributed proportionally to the scale of their deposits.

\subsection{Household behavior}

Workers follow an adaptive heuristic to set their reservation wage: if over the year (i.e., four periods), they have been unemployed for more than two quarters, they lower the asked wage by a stochastic amount. In the opposite case, they increase their asked wage, provided that the aggregate rate of unemployment in the previous period $\left(u_{t-1}\right)$ is sufficiently low. This latter condition is meant to mimic the endogenous evolution of workers' bargaining power in relation to employment dynamics.

$$
w_{i}^{d, t}= \begin{cases}w_{h t-1}^{D}(1-F N) & \text { if } \sum_{n=1}^{4} u_{h t-n}>2 \\ w_{h t-1}^{D}(1+F N) & \text { if } \sum_{n=1}^{4} u_{h t-n} \leq 2 \text { and } u_{t-1} \leq v,\end{cases}
$$


where $u_{h t}=1$ if $h$ is unemployed in $t$, and 0 otherwise.

Workers consume with fixed propensities $\alpha_{1}, \alpha_{2}$ out of expected real disposable income and expected real wealth (Godley and Lavoie, 2007). As workers set their real demand before interacting with consumption firms, they formulate expectations on consumption good prices $p_{h t}^{e}$ :

$$
c_{h t}^{D}=\alpha_{1} \frac{N I_{h t}}{p_{h t}^{e}}+\alpha_{2} \frac{N W_{h t}}{p_{h t}^{e}}
$$

Gross nominal income is given by $w_{h t}+i_{b t-1}^{d} D_{h t-1}+D i v_{h t}$ if the worker is employed. Households pay taxes on income with a flat tax rate $\tau_{i}$. Unemployed workers receive a tax-exempt dole from the government defined as a share $\omega$ of average wages.

\subsection{Government and central bank behavior}

The government hires a constant share of households. Public servants are also subject to a turnover $\vartheta$. Furthermore the government pays unemployment benefits $\left(d_{t}\right)$ to unemployed people $\left(U_{t}\right)$.

The state collects taxes on income and profits (with constant rates $\tau_{i}$ and $\tau_{\pi}$ ) from households, firms and banks and issues bonds $b_{t}$ (at fixed price $\bar{p}^{b}$ and interest $\bar{i}^{b}$ ) which are assumed to last 1 period for simplicity reasons:

$$
\bar{p}^{b} \Delta b_{t}=T_{t}+\pi_{C B t}-\sum_{n \in N_{g t}} w_{n}-U_{t} d_{t}-\bar{i}^{b} \bar{p}^{b} b_{t-1},
$$

where $T_{t}=T_{H t}+T_{C t}+T_{K t}$ are total taxes, $\pi_{C B t}$ are Central Bank profits, $N_{g t}$ is the collection of public workers.

The Central Bank buys bonds not purchased by commercial banks and accommodates banks' request for cash advances. Cash advances are assumed to be repaid after one period and their constant interest rate represents the upper bound for interest paid by banks on customers' deposits. For simplicity reasons, we assume the Central Bank pay no interest on private banks' reserves account. Finally, Central Bank earns a profit equal to the flow of interest coming from bonds and cash advances: $\pi_{C B t}=\bar{i}^{b} B_{t-1}+$ $\bar{i}_{C B}^{a} C A_{c b t}$. Central Bank's profits are distributed to the government.

\section{Baseline setup: challenges in calibration}

Calibration represents a crucial issue for every computational model, in particular when they entail stochastic, path-dependent, possibly non-ergodic dynamics, as it is usually the case in AB models. Technical difficulties, time, and computational limits often prevent the modeller from exploring the entire parameter space and the space of initial endowments of agents, in particular for large-complex macroeconomic model. Models are thus usualy explored in a neighborhood of the baseline scenario. Despite its importance, still only a few $\mathrm{AB}$ macro models provide an exhaustive explanation of the procedure employed to calibrate behavioral parameters, while almost no article provides an explanation of the logic followed to calibrate initial values of stocks and flows.

In section 1.1, we already stressed that a distorted calibration of financial and real initial stocks may be a major source logical and accounting inconsistencies in the model, and we discussed the challenges posed by the initial stock-flow calibration of AB-SFC models. In this section we thus aim to give a contribution in filling what appears to be a major black hole in the literature by proposing a general and replicable procedure to address those challenges.

First, the procedure have to define the initial values of the different types of stocks held by each sector, so that they respect Copeland's quadruple entry principle. Second, aggregates stocks should then be distributed across agents within each specific sector, thus characterizing their overall balance sheet. As described in the previous sections, agents balance sheets are sometimes characterized by the presence of multiple stocks of the same type, which differ in terms of quantity, age, maturity, prices, and liability and asset counterparts. In our model, this is the case for loans in firms' and banks' balance sheets, and capital goods in consumption firms' balance sheets (see section 3.2 and 3.1.4). The third task thus consists in finding a strategy to characterize each specific stock in these collections and assign it to agents who hold it as an asset or a liability.

For this sake, we adopted the following six-step strategy:

1. We derive an aggregate version of the model. 
2. We constrain the aggregate model to be in a real stationary state associated with a nominal steady growth equal to $g_{s s}$. This imply that while all real quantities are constant, all prices and wages are growing at the same rate $g_{s s}{ }^{19}$

3. We numerically solve the constrained model by setting exogenously reasonable values for the parameters for which some empirical information is available (e.g. unemployment rate, mark-ups, interest rates, income and profit tax rates, etc.) or that we want to control (e.g. technological coefficients, number of agents in each sector, distribution of workers across sectors, loans and capital durations). We then obtain the initial values for each stock and flow variable of the aggregate steady state, as well as the values of some behavioral parameters, which are hence compatible with the steady/stationary state (e.g. the propensity to consume out of income, target capacity utilization and profit rates, initial capital and liquidity targets for banks).

4. We distribute each sector's aggregate values uniformly across agents' in that sector. In this way we derive the total value of each type of stock held by agents (e.g. households' and firms' deposits, total outstanding loans and real capital for each firm, total loans, reserves and bonds for individual banks etc.) and agents' past values to be used for expectations (e.g. past sales, past wages, past profits, etc.).

5. To determine the original amount, outstanding values, age of durable stocks we assume that, in each of the periods before the simulation starts, firms have obtained a loan and consumption firms have also acquired new capital batches to replace old capital and maintain their productive capacity. We further assume that the real value (i.e. corrected for inflation) of each of these loans and capital batches was constant. Knowing the constant inflation rate $g_{s s}$ and the amortization schedules for capital goods and loans, we can then derive the outstanding value for each of these stocks, so that the sum of these values is exactly equal to the amount determined in the previous step.

6. In order to set the initial network configuration, we randomly assign a previous period supplier (required for the matching mechanism) to each demand agent on each market, ensuring that each supplier has the same number of customers. Similarly, we assign to households' and firms' deposits, and to firms' loans a randomly selected bank, sot that each bank has the same number (and amount) of deposits and loans with the same number of agents.

The procedure ${ }^{20}$ just explained generates an important symmetry condition on agents' initial characteristics: that is, we start from a situation of perfect homogeneity between agents in order to limit as much as possible any possible bias embedded in asymmetric initial conditions, and we let heterogeneity emerge as a consequence of cumulative effects triggered by the stochastic factors embedded in agents' adaptive rules. Furthermore, by setting initial values based on SS stock-flow norms, we aim to achieve the threefold objective of limiting our arbitrariness in defining agents' initial endowments, restricting the number of free behavioral parameters in the simulation, and find a criterion to set the values of several others.

Table 3 in the appendix shows the exact value of the parameters used in the baseline setup, specifying for each one of them, whether it was exogenously set to determine the steady state ('pre-SS'), derived from it ('SS-given') or following a independent logic ('free').

\section{Results}

After having calibrated the model through the procedure explained in the previous section, we analyzed the baseline setup by running 100 Monte Carlo simulations for 400 periods. Then, we attempted to validate the model output by comparing the properties of our artificial time series with their real world counterparts. Finally, we ran several sensitivity experiments to check the robustness of our results. Sensitivity tests are performed through a parameter sweep on investigated parameters, and replicating each scenario 25 times.

\footnotetext{
${ }^{19}$ The real steady state constraint is motivated by the fact that workers and technological coefficients are fixed in the current version of the model.

${ }^{20} \mathrm{~A}$ detailed description of the whole calibration procedure is presented in appendix $\mathrm{A}$
} 


\subsection{Model Dynamics}

Starting from initial conditions derived as explained in section 4 does not imply in any way that the model dynamics sticks to the steady state employed in the calibration, nor that the initial symmetry condition on agents' setup continues to hold throughout the simulation. As soon as the simulation begins, agents start to react through their stochastic adaptive rules, agents become heterogeneous as a consequence of their dispersed interactions, and the "inherent" dynamics of the model starts appearing.

This sections focuses on the analysis of the properties and determinants of this dynamics. Results presented in this section are obtained by averaging the trends across the 100 Monte Carlo simulations ran with the baseline set-up.

Several forces concur in shaping the dynamics observed in artificial time series. Since the economy lacks any coordinating mechanism supervising agents' decentralized exchanges, thereby ensuring a balanced growth of inflows and outflows across sectors, agents' autonomous interactions may lead to significant changes in the sectoral distribution of real and financial stocks. This in turn affects the stability of aggregates stock-flow norms giving rise to either short term fluctuations or prolonged expansionary/recession phases.

Tracking the evolution of aggregate flows between sectors is thus crucial to understand the mechanics of the economic system. However, a second type of interactions across agents plays a crucial role. This is the interaction between agents within the same class, which takes the form of the competitive processes undergoing on the different markets governing the evolution of microeconomic agents (see section 5.2 for the analysis of these microeconomic properties).

Therefore, while the analysis of inter-sectoral flows can help identifying aggregate imbalances, the analysis of the micro evolution of agents' balance sheet and market structures helps to identify imbalances within a sector.

The analysis of variables trends highlights that the model first experiences a succession of expansionary and recession trends, then converging, in most cases, to a relatively stable configuration of the economy in which main real aggregates fluctuate around stable values, and nominal aggregates grow at similar rates, fluctuating around a steady level. We refer to this situation as a "stochastic steady-state", or "quasi steady-state" (quasi-SS), while the previous time span constitutes the transition phase of the economy.

A common practice in the analysis of Agent Based modeling is that of scrapping the first periods of the simulations and focus on the steady state dynamics of the model. The rationale justifying this choice lies in the fact that AB models are usually characterized by a burn-in period in which the model dynamics is strongly biased by initial conditions. This practice seems to be totally reasonable when assessing the effects of exogenous shocks (e.g. a policy regime switch) hitting the dynamics of a system which has already reached a (quasi) stable configuration. However, we believe it should be taken with a grain of salt when carrying out the preliminary analysis of the model behaviors and properties, that should come before the model is employed for policy purposes.

First, there is an inherent arbitrariness in determining which part of the initial dynamics can be reasonably attributed to possible bias implied by the initial set-up, and which time span reflects instead the inherent behavior of the model. Second, the analysis of the transient phase, for the very fact of being characterized by more pronounced (possibly extreme) fluctuations, can provide useful insights on the mechanisms that generate fluctuations, thereby helping to attain a deeper understanding of the model. Third, agent based models are normally characterized by the presence of cumulative and multiplicative processes that make their dynamics strongly path-dependent. This implies that the properties of the economy in its quasi-stable configuration, such as aggregates levels and aggregates volatilities, depend on the specific path experienced by the economy during the transition phase. Paraphrasing Kalecki, we might say that the long run is nothing but a slowly changing component of a chain of short run situations, with no independent entity; that is, the long-run is a path-dependent sequence of short runs.

For these reasons, we partially depart from the AB macroeconomic literature and discuss first the whole model dynamics, before characterizing the quasi-SS of the model. Figures 2 and 3 present a dashboard of various important variables. The transition phase can be divided into three broad phases.

Phase 1 - Self-sustained Growth The first periods of each simulation are heavily affected by the symmetric condition imposed on agents' within each sector, which generates a rapid increase in unemployment, followed by an equally rapid recovery. ${ }^{21}$

\footnotetext{
${ }^{21}$ At initial conditions all firms revise upwardly the prices of their output whereas only employed workers can increase their reservation wage, thus causing an overall loss of purchasing power. The increased mark-ups however increase profits margins helping to compensate the effect on capacity utilization rates and spurring investment.
} 

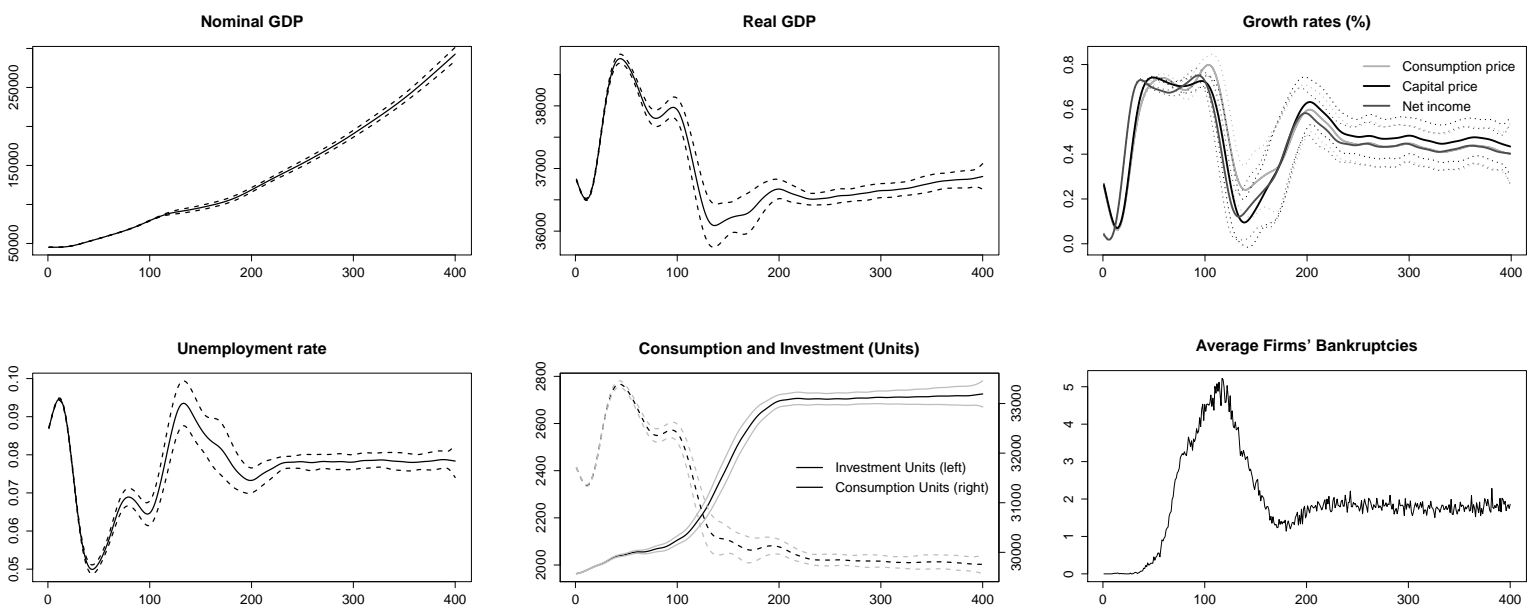

Figure 2: Top Left: Nominal GDP. Top Center: real GDP. Top Right: net-income, consumption prices, and capital prices rates of growth. Growth rates of prices have been computed using average market prices (weighted for firms' market shares). Bottom Left: Unemployment. Bottom Center: Investment and consumption (real units). Bottom Right: number of firms' bankruptcies. Continuous lines are mean trends over Monte Carlo Simulations. Dashed lines are trends standard deviations across Monte Carlo runs.

The time between periods 10 and 45 display a self-fuelling real growth process driven by real consumption: higher demand leads to higher employment which further stimulates demand also through the wages inflationary process. Figure 2 shows that during this phase households net-income rises steadily at a higher (and increasingly) pace than inflation. Demand for consumption goods thus keeps rising. Real investment is stable since lower profit margins offset the increased capacity utilization rates. Consumption firms' returns in fact are squeezed by the reduction of realized markups arising from price and wage dynamics, ${ }^{22}$ and by the increased prices of capital goods.

The reduction of profit margins reduces the amount of internal funding available to finance production and investment, whereas the rise of wages, employment, and capital prices increases expenses. On average, consumption firms are thus more reliant on external finance. More credit, however, means greater amounts of liquid resources being diverted towards debt service so that the loans/deposit ratio starts to increase, see figure 3. Increasing firms' indebtedness is somehow tempered by a tightening of banks credit rationing behavior, as a consequence of falling operating cash flows.

The situation at the micro level is far more variegated. Some firms outperform and experience increasing profits while some undergo a dramatic drain of liquid resources.
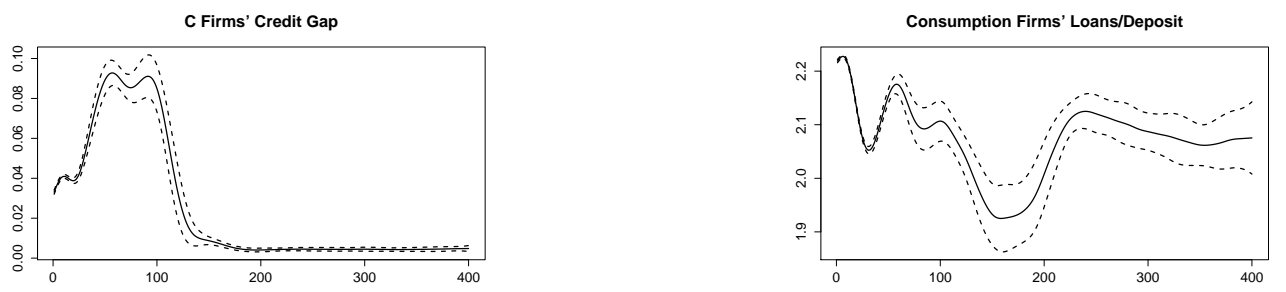

Figure 3: Left: share of unsatisfied demand for credit. Right: Consumption firms' loans to deposit ratio. Continuous lines are mean trends over Monte Carlo Simulations. Dashed lines are trends standard deviations across Monte Carlo runs.

Phase 2 - Trend inversion and great recession Wage growth rates tend to stabilize around period 40 so that inflation catches up and eventually surpasses nominal wage growth, compressing household purchasing power. In the meantime (around period 35) some firms default, not being able to pay wages and honor their outstanding debt. Firm defaults exerts three effects: wages not paid to workers reduce

\footnotetext{
${ }^{22}$ The lag characterizing consumption prices dynamics, compared to net-income growth, can be explained by the fact that consumption prices are set as an adaptive mark-up over expected unit labor costs. Whenever wages growth accelerates, firms tend to underestimate labor costs, so that realized mark-ups are lower than desired ones. For expectations to catch up with actual values, it is required that rates of growth stabilize.
} 
current demand; fire sales of defaulted firms' capital goods reduce household deposits (see section 3.3); firms' default generally implies a bad-debt affecting banks' balance sheets and capitalization.

These processes revert the expansionary trend triggering a vicious spiral between successive slumps in demand and peaks of unemployment between period 45 and $130 .{ }^{23}$ Only some of the firms are able to react to the adverse economic environment and continue to grow, while an increasing number experiences a deep crisis so that the number of defaults keeps rising, fostering a process of increasing concentration on real markets.

Phase 3 - Recovery and convergence to the quasi steady-state The positive spread between the fall in wages and that in prices, while reducing households purchasing power, tends to increase consumption firms' profit margins. Similarly, the fall of capital prices reduces firms' investment-related outlays exerting a positive impact on the profit rate. Finally, defaulted firms are allowed to restart without the burden of their previous debt. These aspects concur to generate a spur of investment, notwithstanding the fall of average capacity utilization rates. Real consumption hits the ground around period 130 and then stabilizes. The system progressively converges to the quasi steady-state position with unemployment fluctuating just below $8 \%$. After some period, real investment also stabilizes around the level required to keep consumption firms' capacity unaltered. ${ }^{24}$

\subsection{Validation}

In the final part of 1.1, we argued that checking the logical and accounting coherence of a model should be a necessary step of the overall validation process of an $\mathrm{AB}$ macroeconomic model. Albeit a proper calibration of initial stocks and flows and a correct description of the accounting records arising from exchanges between microeconomic agents should be theoretically enough to ensure also the aggregate accounting coherence, in practice it is not unusual to observe leakages during the model implementation. This is often the case for large complex AB models embedding a variety of agents and featuring complex timeline of events and many types of heterogeneous real and financial stocks. We then propose two complementary methods to avoid misspecifications, based on the accounting matrices traditionally employed in the aggregate SFC literature:

1. The first method consists in deriving the Transaction Flow Matrix and Full Integration Matrix (Godley and Lavoie, 2007) of the model. Compliance with Copeland's quadruple entry principle requires that every row and column of the matrices sum up to zero in every single moment of the simulation. This reflects the basic facts that every outflow by an agent should also be an inflow for some agent, and that every financial assets of an agent is also a liability for some other agents. Deriving the aggregate accounting matrices brings two further advantages: it clarifies the interdependencies between flows in the economy and it provides a synthetic picture of the evolution of flows between sectors and sectors' accumulation of real and financial stocks, thereby helping to understand the structural dynamics of the model.

2. Since the full integration matrix connects the flows and the stocks of the model, another intuitive way to check the models SFC is using the economy aggregate balance sheet. The method consists in checking that the sum of the net worth of all the agents in the economy (including government and central bank) is exactly equal to the values of real assets in every simulation round. This can be easily explained by the fact that real stocks are the only assets in the economy which do not have a liability counterpart. Conversely, every financial stock should be an asset for someone and a liability for someone else in the economy, so that assets and liabilities offset each other in the process of summing up.

Tables 1 and 2, in appendix, provide an example of the two checking procedures applied to the initial period of our simulations. ${ }^{25}$ The artificial economy displays two types of real assets, inventories and

\footnotetext{
${ }^{23}$ As a consequence, wages fall and inflation slows down, although the lag characterizing prices dynamics induces a further loss in household purchasing power

${ }^{24} \mathrm{It}$ is interesting to notice that the level of real consumption and real investment in the new steady state are respectively lower and higher than in the initial situation while unemployment is almost the same, implying a redistribution of employees between consumption and capital firms. In the quasi steady-state neither the aggregate profit rate nor the capacity utilization rate are at their target levels. Instead, the former is higher while the latter is lower, compensating each other in determining the level of investment.

${ }^{25}$ For obvious space reasons, we omit the tables referring to other periods of the simulation.
} 
consumption firms' capital. The reader can then easily verify that the total net worth of the economy exactly matches the total accounting value of these items.

Having checked that the models satisfies these accounting conditions over the complete simulation time-span, we proceed to the empirical validation of the baseline results. For this sake, following a well established practice, we compare the properties of our artificial data with a set of empirical stylized facts collected from other contributions in the AB macroeconomic field, as well as from other empirical studies. Results suggest that our model provides a good approximation of the properties displayed by real world data, ranking among the best contributions provided by the literature for the number and the variety of micro and macroeconomic stylized facts matched.

\subsubsection{Macro-stylized facts}

Following Assenza et al. (2015), we first compared the volatility, auto, and cross-correlation structures of main aggregate variables in the model with their empirical counterparts. ${ }^{26}$ Since our model is calibrated such that one period corresponds to a quarter, 400 periods correspond to 100 years. Trends and cycle components have been separated using the Hodrick-Prescott filter.

Figure 4 presents the cyclical component of the artificial time series for GDP, unemployment, investment, and consumption, each one normalized by the trend in order to allow a comparison on the same scale. The properties of artificial time series are very close to observed ones. The figure shows that investment and unemployment volatility are significantly higher than real GDP volatility, while consumption is slightly less volatile than output. Using US data, Carlin and Soskice (2015) find that the relative standard deviation (compared to real GDP) of consumption is $0.80,4.61$ for investment, and 8.22 for unemployment. These values are fairly close to ours: consumption has a relative standard deviation of 0.79 while investment has a relative standard deviation of 4.45. Unemployment instead shows a higher relative volatility (13.25) compared to empirical data, which can be explained with the relative ease to fire and hire in the model, where firms are immediately able to adapt the number of employees to the level of production planned, thus making employment more volatile.
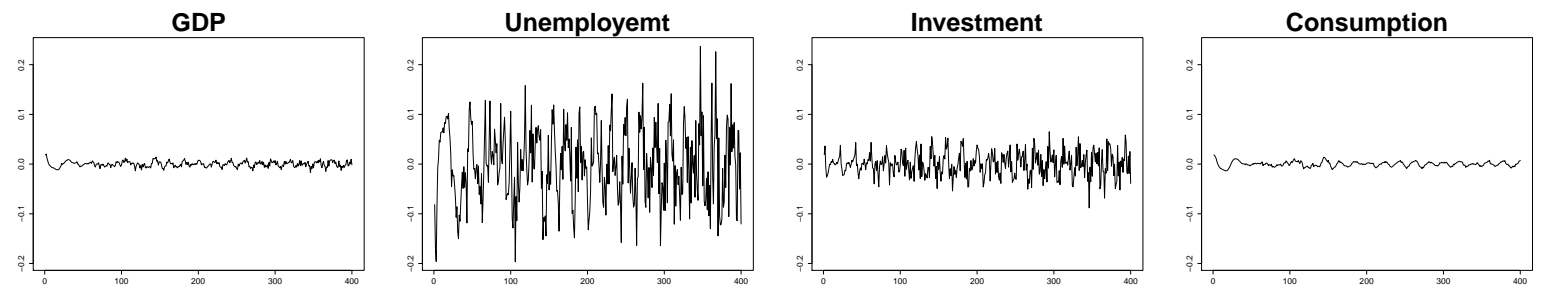

Figure 4: Cyclical components of simulated times series for Real Output, Unemployment, Investment, and Consumption.

In the left panel of figure 5, we show the artificial and observed auto-correlations of the de-trended series up to the $20^{\text {th }}$ lag. The auto-correlation structure of artificial times series looks remarkably similar to the auto-correlation function of observed real data. All variables have strong positive first order auto-correlations. $^{27}$

The right panel of figure 5 shows the cross-correlations between the cyclical component of real output at time $t$ and of real output, unemployment, real investment, and real consumption at time $t-l a g$. The position of the peak in each correlation figure indicates whether the variable is lagged, coincident or leading with respect to output. The shape, dimension and the position of the peak of our simulated time series provide a very good fit of the properties shown by real time series.

The fundamental properties of our simulated time series highlighted above are robust across the experiments performed in the sensitivity analysis, ${ }^{28}$ though the absolute values of the correlations slightly change. In particular, investment always appears to be pro-cyclical and coincident with real output, unemployment is counter-cyclical and lagged by a quarter, while consumption is always pro-cyclical and

\footnotetext{
${ }^{26}$ Real time series are taken from the Federal Reserve Economic Data (FRED): they are quarterly data ranging from 1955-01-01 to 2013-10-01 for unemployment (not seasonally adjusted, FRED code: LRUN64TTUSQ156N) and ranging from 1947-01-01 to 2013-10-01 for investments, consumption and GDP (FRED codes: PCECC96, GPDIC96, and GDPC1 respectively).

${ }^{27}$ A remarkable difference, however, has to be found in the $20^{\text {th }}$ auto-correlation of investment and unemployment which look significantly higher than real ones. This inconsistency is easily explained in light of our assumption that real capital has a duration of 20 periods before being scrapped off. This introduces a significant cyclical component in real investment.

${ }^{28}$ For space reasons we omit the figures concerning the sensitivity scenarios. These are available online at: https://github.com/S120/benchmark
} 
Auto-correlations

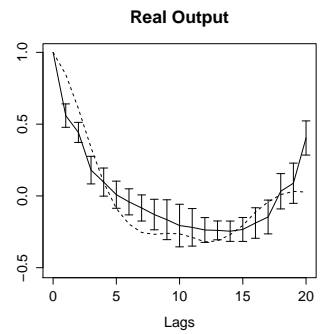

Unemployment

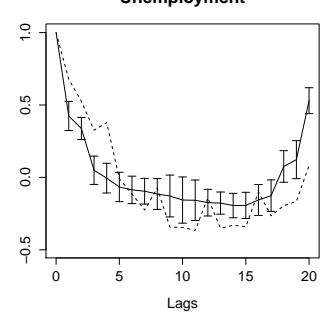

Real Investment

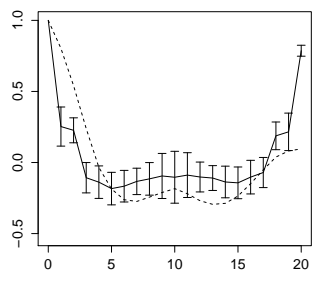

Real Consumption

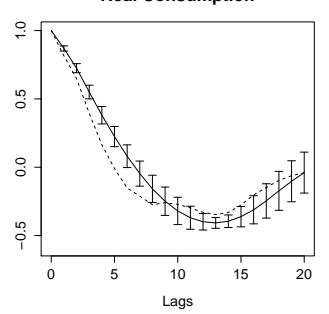

Cross-correlations
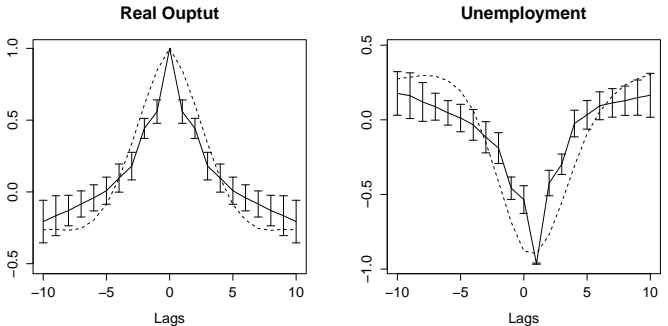

Lags
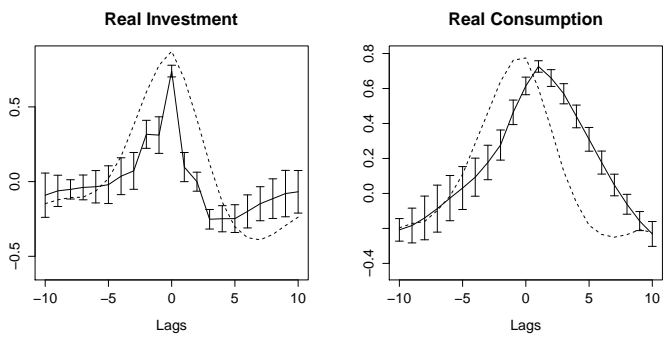

Figure 5: Left Panel: Average artificial (continuous) and real (dashed) auto-correlations of the de-trended series up to the 20th lag. Bars are standard deviations of Monte Carlo average auto-correlations. Right Panel: Average artificial (continuous) and real (dashed) cross-correlations of the de-trended series up to the 10th lag. Bars are standard deviations of Monte Carlo average cross-correlations.

may be either coincident or slightly lagged by a quarter according to the specification employed. This suggests that the fundamental properties of the correlation structure observed in artificial data is an inherent property of the model rather than being dependent on a specific parametrization. That is, changing the parameters of the model, obviously changes the behavior of agents (e.g. making banks less or more prone to grant credit) affecting the evolution of main economic aggregates both in the short and long term. However, the way these aggregates impact on each other, which is captured by the underlying correlation structure of macroeconomic variables, is kept unaltered in its main properties. ${ }^{29}$
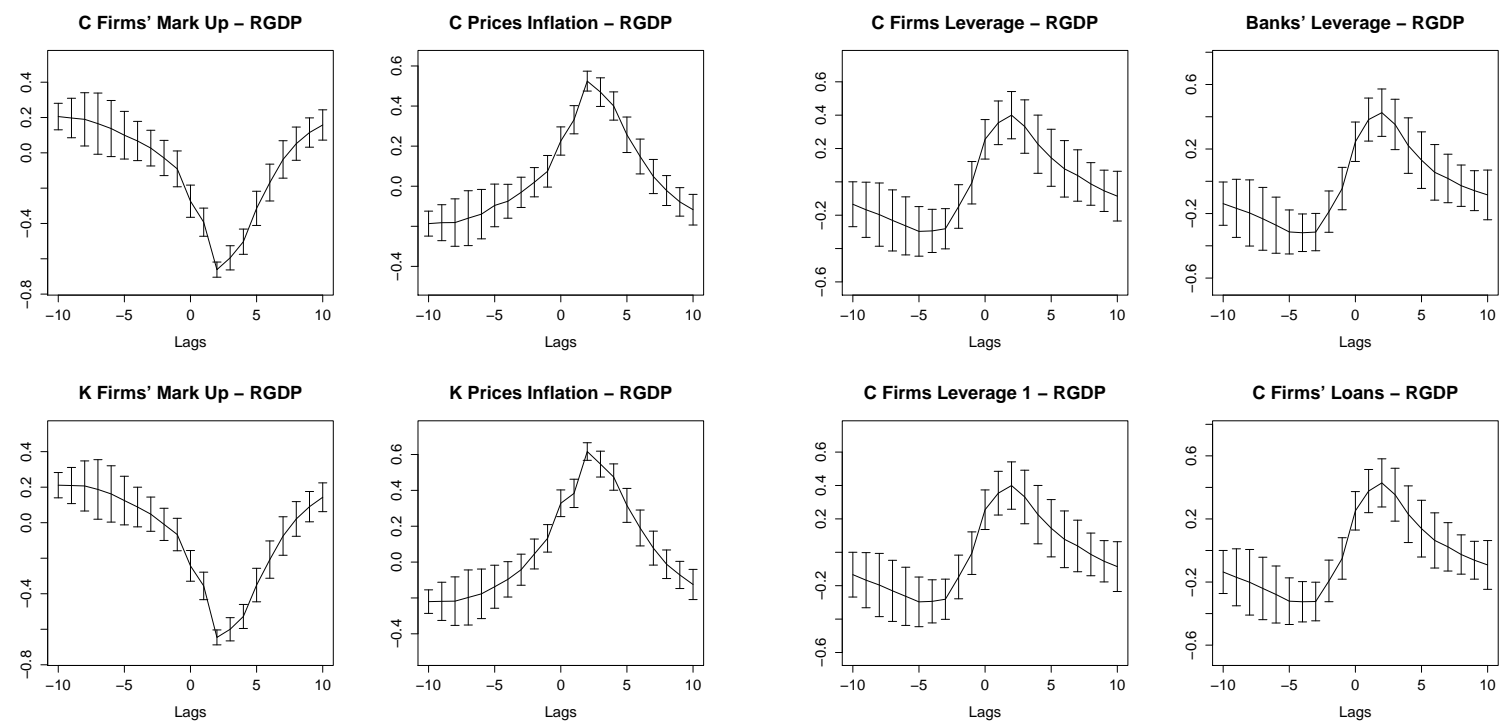

Figure 6: Average artificial cross-correlations of the de-trended series up to the 10th lag. Bars are standard deviations of Monte Carlo average cross-correlations. Consumption firm's leverage can be defined in two ways: total debt to net worth ratio (top graph) or total assets to total debt ratio (bottom graph).

The model also reproduces several other important macroeconomic stylized facts observed in reality. Figure 6 (left panel) highlights that, in accordance with the empirical evidence on business cycles, inflation

\footnotetext{
${ }^{29}$ This is consistent with economic reality where, despite the changes in agents' habits and 'animal spirits', the properties of the correlation structure of macroeconomic aggregates is fairly stable, thus justifying their adoption as a criteria to validate macroeconomic models.
} 
is pro-cyclical and lagging (tending to build up during an expansion and fall after the cyclical peak), whereas mark-ups are counter-cyclical and lagging, see Bils (1987) and, for a survey of the literature on business cycles and countercyclical markups, Rotemberg and Woodford (1999). ${ }^{30}$

In addition, the model assumption that firms revise adaptively their prices every period of the simulation (i.e. a quarter) is fairly in line with the evidence provided in Klenow and Kryvtsov (2005) that find a monthly frequency of price changes of $29.3 \%$ (implying a pseudo-average duration of 3.4 months). Their paper also highlights that, despite moderate inflation is the norm, there is no evidence of prices downward rigidity at the microeconomic level, as price decreases account for $45 \%$ of total price changes. Price decreases in a context of moderate inflation (see below) are not uncommon (though less frequent) in our model as well, where the frequency of price-decreases ranges between 0.30 and 0.40 aproximately across the baseline Monte Carlo runs.

Figure 7 shows that changes in inventories are pro-cyclical whereas the inventories/sales ratio is counter-cyclical as we would expect by looking at the empirical literature (see Bils and Kahn, 2000). Usually, during a business downturn, firms let their inventories decline producing less. In the model, a drop in real sales reduces the desired amount of inventories which is defined as a constant share of sales. However, since unsold inventories are accumulated, the drop is less than proportional with respect to sales, explaining the counter cyclical relation between the inventories/sales ratio and real output. When the downturn reaches its turning point, firms fall short of inventories as a consequence of the rise in sales ${ }^{31}$ and revise upwardly, with a lag, the amount of inventories they want to hold, increasing production. Inventories thus grows with a lag with respect to sales during expansions until the cycle is eventually reverted.
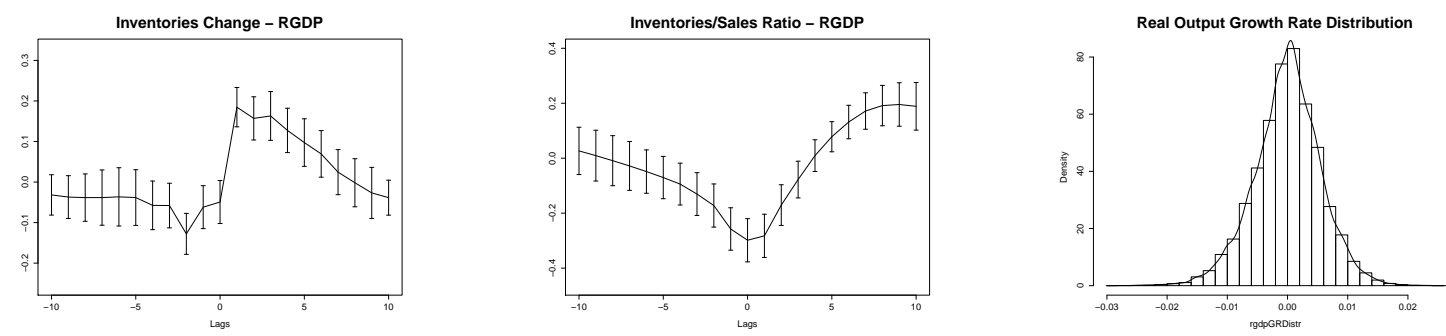

Figure 7: Left and Center: artificial cross-correlations with real output of the de-trended series up to the 10th lag. Bars are standard deviations of Monte Carlo average cross-correlations. Right: Growth Rates tent-shaped distribution. The continuous line is the kernel density estimation.

Figure 6 (right panel) shows that banks' leverage, defined as total loans over banks' net worth, is pro-cyclical displaying a cross correlation with real GDP at lag 0 equal to 0.25 , in line with the statistics provided by Nuño and Thomas (2013) which estimates a correlation of 0.18 and ranging between 0.12 and 0.36 , according to the definition of leverage adopted. This is a consequence of the pro-cyclical behavior of firms' total debt (explained below): the endogeneity of money in the model and the adoption of stock flow consistent rules implies that, as in reality, every new loan is accompanied by the creation of a new deposit of equal value, so that the loan creation process corresponds to an expansion of banks' balance sheets which leaves unaltered their net worth (Barwell and Burrows, 2011; Jakab and Kumhof, 2015; Benes et al., 2014; McLeay et al., 2014). Given the absence of other financial assets, such as real estates or shares, whose value can be affected by the rise of liquid assets circulating in the economy, every new loan thus increases the numerator of the leverage while keeping constant the denominator.

In addition to the evidence on leverage cyclicality, Nuño and Thomas (2013) find that banks' leverage is almost twice as volatile as real output. This is consistent with our finding that banks' leverage relative standard deviation is equal to 1.69 .

Firms' leverage and firms' total debt are pro-cyclical (figure 6, right panel), and show a crosscorrelation structure similar to banks' leverage that can be explained as a consequence of the fact that consumption firms' credit account for the vast majority of banks' loans, capital firms' debt representing

\footnotetext{
${ }^{30}$ The pro-cyclicality of inflation is explained by the fact that firms change adaptively their desired mark-up according to their sales performance, so that during upturns they increases (on average) prices, and vice-versa. However, the markup is then applied on expected unit labor costs. If wages keep rising as a consequence of lower unemployment, realized unit labor costs will be higher than expected ones, more than compensating the increase in desired markups. The opposite happens during dowturns, thus explaining the counter-cyclical behavior of markups.

${ }^{31}$ Actually this can happen even before the turning point if the recession slows down and firms underestimate the demand for their products.
} 
a minor share of banks outstanding credit. ${ }^{32}$ The pro-cyclicality of firms' total debt is another wellknown stylized fact, as shown by C. and Morgan (2006); Leary (2009). In the model, firms increase their debt during expansion phases to fund increased investment and possibly as a consequence of inflationary pressures on wages, which tend to reduce the sources of internal funding. Banks may accommodate the demand for loans as a consequence of an increased reliability of firms', proxied by their operating cash flows. ${ }^{33}$ The empirical evidence on firms' leverage is more controversial and varies across countries and industries. Halling et al. (2012), for example, finds that leverage by non-financial corporations is countercyclical in "civil law' countries and countries with low debt-holder protection, whereas it is significantly pro-cyclical in "common law" countries and countries with relatively high debt-holder protection, such as the US.

Finally, real output growth rates generated in the model show the well-known tent-shaped leptokurtic distribution (with excess kurtosis $\approx 0.70$ ) observed in real world (Fagiolo et al., 2008), as displayed in figure 7 (right). In addition, although using constant labor and capital productivities and a fixed number of workers and thus impeding ever-lasting real growth, the model generates exponential longterm nominal growth with moderate inflation, as observed in reality. In the baseline quasi steady-state, prices of consumption goods and nominal GDP grow at an annual rate of approximately 1.6-1.8\% (see figure 2).

\subsubsection{Micro-stylized facts}

The model is also able to reproduce several important stylized facts at the microeconomic level. Despite agents within each class are almost perfectly homogeneous at the beginning of our simulations, heterogeneity emerges during the simulation, first as a consequence of the inherent stochasticity affecting agents' interactions and adaptive behaviors, and then as the result of the path-dependent/cumulative effects arising from agents' competition on real and financial markets. The selection processes affects the evolution of market structures, from an initial situation in which firms' market shares are all equal towards a more concentrated market.

Following van der Hoog and Dawid (2015), figure 8 plots the evolution of consumption and capital firms' market shares. For graphical reasons, we plot the values referring to 20 firms belonging to each class, over the time span (200:400) of a single simulation. The plots show that market shares in the model are not only characterized by an high degree of heterogeneity among firms, but also by high persistency, both for consumption and capital firms.
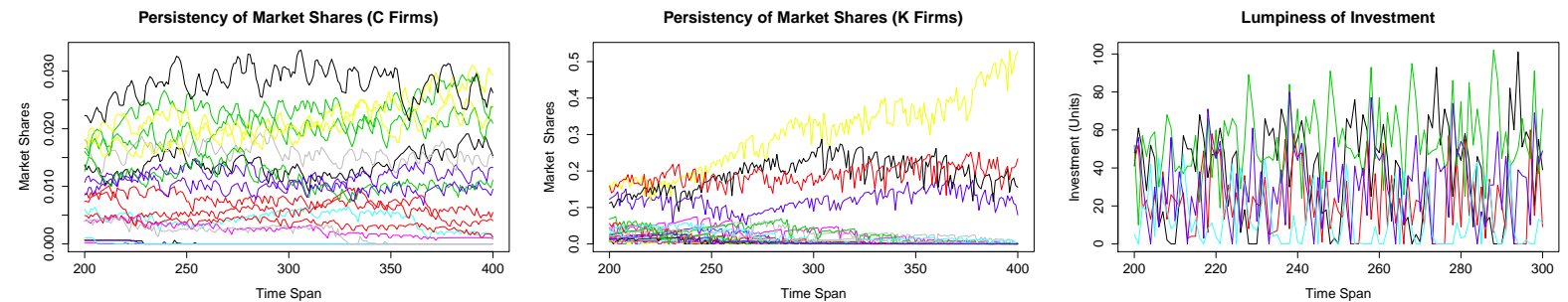

Figure 8: Market shares persistency (left and center): Lines refer to 20 consumption (left) and capital (right) firms in the time span (200:400) of a single run. Invesment lumpiness (right): lines refer to 5 consumption firms in the time span (200:300) of a single run.

Competition in consumption and capital markets steers the evolution of industries structure over time. In line with empirical evidence, distributions of firm sizes appear to be right skewed and fat-tailed for both capital and consumption firms, regardless the measure used for consumption firm size (i.e. real sales or firms' productive capacity). ${ }^{34}$ The fat-tailed, right skewed nature of firm size distribution, with upper-tails made of few large firms, is well know since Gibrat's seminal contribution though the shape of the distribution may vary considerably across countries and industries.

\footnotetext{
${ }^{32}$ This in turn is explained by the fact that consumption firms' demand for loans is mainly driven by investment needs, whereas capital firms possibly demand credit only to fund production.

${ }^{33}$ Notice however that it might be the case that firms expand their indebtedness by a lower degree than desired if banks perceive the increased demand for loans as too risky. This is reflected in the dynamics of the credit gap in the baseline, i.e the share of unsatisfied demand for credit, which can increase even during expansions.

${ }^{34}$ Consumption and capital firm size distribution, as measured by firms' sales, has a skewness equal to 0.83 and 2.88 respectively, while using productive capacity the skewness for consumption firms is equal to 0.55 . The excess kurtosis for firms' sales distribution is equal to 0.49 for consumption and 10.20 for capital firms thus characterizing both distributions as leptokurtic. Consumption firms' capacity distribution has an excess kurtosis equal to 0.11.
} 
For a long time, the conventional wisdom maintained that expected firm growth rates are independent of size (Gibrat's Law), and that the firm size distribution is stable and approximately log-normal. Stanley et al. (1995) confirm that, like in earlier studies, the log-normal distribution fits the data well except for the upper tail, which contrary to the common belief are thinner rather than fatter. On the same line Cabral and Mata (2003) finds that the log-normal fits well data for firms with publicly available accounting data, while using more complete datasets the firm size distribution is more right-skewed, though evolving over time toward a more symmetric one if we consider firm size distribution for groups of different ages. Bottazzi and Secchi (2003) finds that the empirical densities of US firm size distributions display a remarkable degree of stationarity over time and are very well approximated by a log-normal fit, confirming the results of Stanley et al. (1995). Axtell (2001) on the contrary finds that firm size distribution in the US can be approximated by Zipf distribution, that is a Pareto distribution with unitary exponent. However, using data from G7 countries Gaffeo et al. (2003) finds that only in limited cases the exponent is equal to -1 , although data are broadly consistent with a power law distribution. ${ }^{35}$

Figure 9 provides the log-log plot of firm size distribution photographed at period 350 of the 100 Monte Carlo Simulations. ${ }^{36}$ The graphs shows that firms are highly heterogeneous with respect to their size, and their size distribution displays fat tails. ${ }^{37}$ The graphs also show the log-normal (green line) and Pareto (red) fits of the upper tails, showing that both types of distributions roughly fit the data, although the log-normal fit generally seems to be preferred, in accordance with the empirical evidence in the wake of Gibrat's contribution (Stanley et al., 1995). In order to fit the data, we follow the procedure explained in Clauset et al. (2009) for the Power Law estimation and we then perform a bootstrap to check the plausibility of the power law distribution hypothesis, which is accepted for p-values above $0.1 .^{38}$ In all cases the p-value is very high (0.84 and 1 for consumption firms' size distribution based on productive capacity and sales respectively, 0.99 for capital firms real sales distribution) indicating that the power law hypothesis is plausible. Then, we estimate with a similar procedure the log-normal and we formally compare the power law with the alternative log-normal hypotheses via Vuong's likelihood ratio test. A low p-value indicates that we can reject the null hypothesis of both distributions being equally far from the true one. Whenever the likelihood ratio is significantly different from zero, then its sign indicates whether the log-normal is favored over the power-law model or not. For consumption firms we obtain that the log normal is favored regardless the measure of size adopted, ${ }^{39}$ whereas for capital firms' the $\mathrm{p}$-value is 0.85 and the ratio close to 0 , indicating that the null hypothesis that both distributions equally fit the data cannot be rejected.
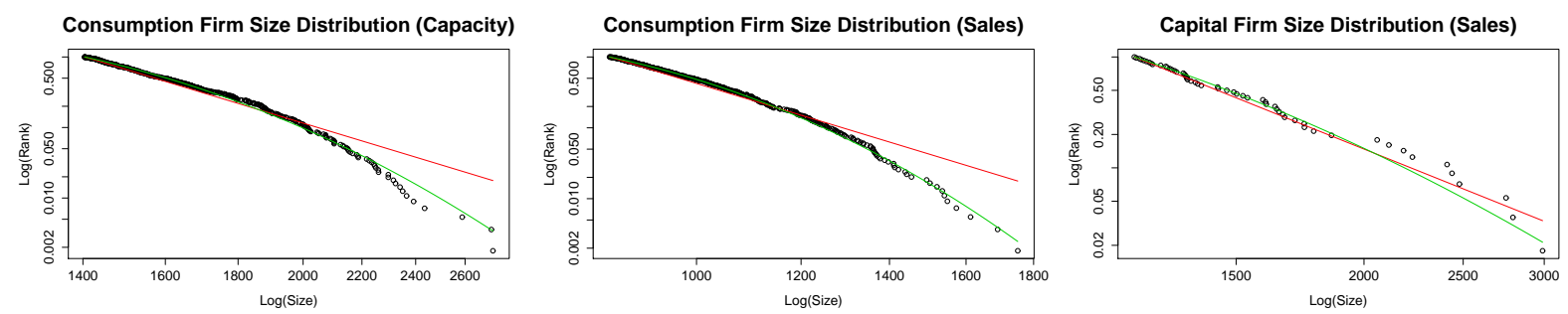

Figure 9: Consumption and Capital firms size distributions. The figures also displays the log-normal (green) and power-law (red) fits of the right tails of the sample distributions.

In addition, the model is able to reproduce a certain degree of lumpiness in investment at the micro

\footnotetext{
${ }^{35}$ However, we shall stress that this divergence of results is somehow mitigated by the fact that the log-normal and power-law distributions are intrinsically connected. Indeed, small variations from the pure multiplicative stochastic process underlying the Gibrat's law can change the result from one to the other, see Aitchison and Brown (1957) and Sahota (1978). In particular, several contribution shows that a power-law distribution can be obtained by adding a reflective barrier (Levy and Solomon, 1996) in the form of a lower bound, or an additive noise, or a stochastic resetting of the size (Nirei and Souma, 2004) to the stochastic multiplicative model.

${ }^{36}$ The same plots has been analyzed for several periods between 300 and 400 showing that, in accordance with empirical evidence, firms' size distribution is fairly stable after the model reaches its quasi-SS.

${ }^{37}$ Jarque-Bera tests for normality in the distribution of consumption and capital firm sizes all yield a p-value equal to 0 , indicating that the normal distribution hypothesis must be rejected. The $\chi^{2}$ statistic is equal to 629.58 for consumption firms' capacity, 896.076 for consumption firms' sales, and 12546.87 for capital firms' sales.

${ }^{38}$ The p-value indicates the frequency of cases in which the distance of sample data from a theoretical power law having lower bound and exponent equal to the estimated ones is lower than the distances of the set of synthetic data sets randomly drawn from the same theoretical power law model. A p-value close to 1 then indicates that the difference between sample data and the model can be attributed to statistical fluctuations alone.

${ }^{39}$ More precisely, we obtain a p-value equal to 0.001 and a test statistic equal to -3.2 when employing firms' capacity, and a p-vale of 0.005 and likelihood ratio of -2.8 when we use firms' real sales instead.
} 
level, as observed in real world. For graphical clarity reasons, figure 8 (right) displays real investment, measured in capital units, for 5 randomly chosen consumption firms over the time span (200:300) of a single simulation in the baseline scenario. The plot highlights that investment is not smoothed over the time span, but rather displays successive spikes, followed by periods in which investment is significantly lower, or even null. Firms investment depends on their expected sales, the stock of unsold inventories, and the profit rate. When firms, as a consequence of a drop in sales or profits (either related to the business cycle or to competitive pressures) end up having a capacity of production higher than the desired one, they replace just a part of capital vintages reaching obsolescence, or they even refrain from investing. On the contrary, investment can rise significantly when things are going well in order to increase firm's productive capacity. Since a real capital batch acquired in a given period is scrapped all at once when it reaches technical obsolescence (20 periods), rather than being scrapped gradually (as it happens for its financial amortization), these changes in investment tend to replicate in subsequent periods. These cyclical effects overlap to the effects caused by new changes in market conditions on the desired production capacity. This generates the lumpy and cyclical patterns of investment observed in the figure as an emergent property of the model, i.e. without having embedded this feature ex-ante in the behavior of agents'. ${ }^{40}$
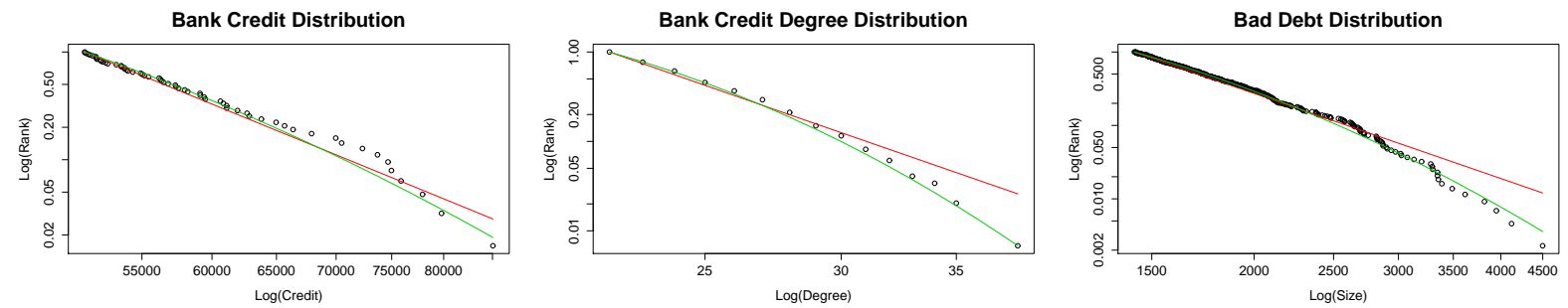

Figure 10: Bank Credit Distribution (left), bank credit degree distribution (center), and bad debt distribution (right). The figures also displays the log-normal (green) and power-law (red) fits of the right tails of the sample distributions.

In figure 10, we analyze the distribution of banks' credit degree and bank credit through the log-log plots obtain by collecting data referring at period 350 of the 100 simulations run for the baseline. As pointed out by Lux (2014), while firm size distribution and its determinants have been throughly studied over the last eighty years, it seems that the banking sector had been a blank spot, primarily, but not exclusively, as a consequence of the lack of data available on the size and distribution of activity within the banking sector. The empirical evidence available on banks credit distribution is thus limited, in particular for credit extended to non-financial firms. Nonetheless, de Masi and Gallegati (2007), using Italian data, presents some evidence on the banks-firms network topology. They find that the number of degree of banks is far higher than that of firms, and that banks' degree distribution shows fat-tails, suggesting that some banks finance a large number of firms, thereby having higher outstanding credit than predicted by a normal distribution. Our figures are in line with these findings under both respects. Both credit and degree distributions of banks have positive skewness (equal to 0.27 for bank credit degree distribution and 0.69 for bank credit distribution) suggesting the presence of fat tails. Normality Jarque-Bera tests reject the normal distribution hypothesis for both distributions. ${ }^{41}$ Figure 10 displays the log-log plot of the two distributions with the log-normal and power-law fits of the right tails, obtained following the same methodology adopted for firm size distribution. In addition, while most firms end up having 1 to 3 links to different banks, the average degree of banks is 13.37. Graphically this can be also observed in figure 11 which displays the evolution of the community structure of the banks-firms directed credit network from the initial symmetric situation - where firms' are assumed to have the same number of links (i.e. loans) to the same number of banks and banks are assumed to have the same degree - to the final period of the simulation.

Finally, the distributions of firms' bad debt (figure 10, right) and firms' bankruptcies reflect the properties observed in the empirical counterparts: ${ }^{42}$ being both right skewed and characterized by positive excess kurtosis, thereby suggesting the presence of fat-tails. ${ }^{43}$

\footnotetext{
${ }^{40}$ Indeed, an alternative way to generate lumpy investment is to impose a "trigger" level of investment in firms' investment heuristics which characterizes firms expansionary investment strategy as a "yes or no" decision (see for example Dosi et al. (2006)).

${ }^{41}$ We obtain $\mathrm{p}$-value $=0, \chi^{2}=26.074$ for credit degree distribution, and p-value $=0, \chi^{2}=77.912$ for banks' credit distribution.

${ }^{42}$ In particular, Di Guilmi et al. (2004) and Delli Gatti et al. (2004) suggests that both distributions have right tails scaling down to a Pareto.

${ }^{43}$ The skewness is equal to 2.16 for firms' bad debt and 1.97 for firms' bankruptcies, whereas the former has an excess
} 

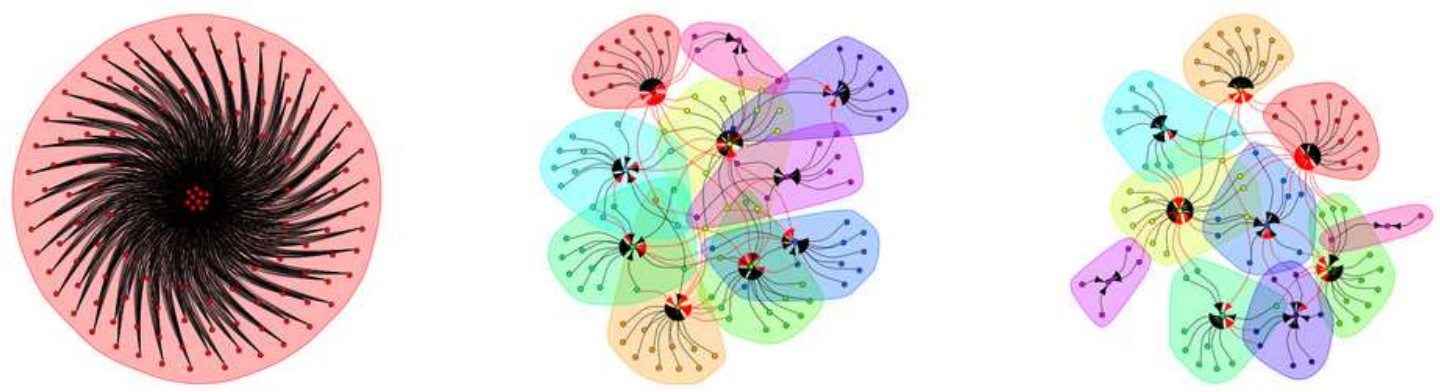

Figure 11: Credit Network Community Structure: arrows point from liability holders (firms) to asset holders (banks).

\subsection{Robustness checks}

Our previous analysis shows that investment and credit demand behaviors by firms on the one side, and credit supply behaviors by banks on the other, play a crucial role in steering the economy across successive expansionary and recessive phases. The question of how different parametrizations of investment and credit behaviors affects the transition phase, the properties of the economy in the long run, and the robustness of the cyclical properties employed to validate the model then arises.

We performed sensitivity experiments on the parameters referring to investment and credit behaviors: ${ }^{44} \varsigma_{c}$ and $\varsigma_{k}$, defining banks' risk aversions in assessing consumption and capital firms reliability, $\gamma_{1}$ and $\gamma_{2}$, the weights given to the profit rate and capacity utilization arguments in consumption investment, and $\sigma$ expressing firms' precautionary deposits. Each sensitivity analysis ${ }^{45}$ was carried out by performing a parameter sweep over the parameter of interest. The range of variation for each parameter is specified in table 3, in the appendix. For each parameter configuration (i.e. for each scenario) we ran 25 Monte Carlo simulations.

Our results confirm that all the cyclical properties of our artificial time series discussed in section 5.2 continue to hold under all the scenarios investigated, and provide a very good match of the empirical stylized facts discussed in the literature. This suggests that, although changes in the parameters employed in the sensitivity experiments may affect the transition and long term dynamics of the model, the causal structure of the model and the structural inter-dependencies between its main variables is not subverted. More important, this provides some (non exhaustive) evidence for the fact that the model ability to replicate macroeconomic cross-correlations is not originated by the specific parametrization employed.

As a final remark on the robustness of our results, we are aware that the way agents make expectations would also deserve some attention: although the simple adaptive expectations scheme employed in the model is well-established in the literature (recent examples are Assenza et al., 2015; Dosi et al., 2010, and later works), several authors has recently stressed the relevance of heterogeneous expectations in models employed for policy analysis (Assenza et al., 2013b,a). On the same line, Salle et al. (2013) proposes a model where agents' simple adaptive heuristics are continuously revised through a learning process. Despite this type of application goes beyond the objective of the present paper, we believe that heterogeneous expectations and endogenous learning are very promising lines of development in the $\mathrm{AB}$ literature, and would represent a valuable addition to the present model as well. ${ }^{46}$

\footnotetext{
kurtosis equal to 2.16 and the latter 1.32. The tests rejects the normality hypothesis for both distributions with p-value equal to 0 in both cases and test-statistic equal to 19000.74 and 13378.20 respectively. The bootstrapping hypothesis tests on the power law estimated models confirm that the right tails of both distributions are broadly compatible with a Powerlaw (p-value equal to 1 for the bad debt distribution and 0.29 for firms' bankruptcies), although the log-likelihood tests suggest that the simulated distribution is better approximated by a log-normal, diverging in this respect from the evidence provided by Di Guilmi et al. (2004); Delli Gatti et al. (2004).

${ }^{44}$ Admittedly, several other parameters are likely to exert an impact, such as the rate of taxation, the threshold employed in workers reservation wage function, or households' propensities to consume. However, besides space and tractability reasons, let us point out that the values of these parameters have been jointly derived (see appendix A.1) in order to be compatible with the SFC initial setup. Changing their values would then impose an exogenous shock on the model or require to change the initial configuration of stocks and flows, in both cases preventing a direct comparison with the baseline calibration.

${ }^{45}$ The figures and tables summarizing the results of the five sensitivity experiments can be found on the platform web page: https://github.com/S120/benchmark. For a discussion of the different scenarios see: http://papers.ssrn.com/sol3/papers.cfm?abstract_id=2664125

${ }^{46}$ In order to move in this direction, we made a preliminary investigation by running 5 simulations using different specifications of the 'anchoring and adjustment' and 'trend-following' schemes presented in Assenza et al. (2013b). Preliminary
} 

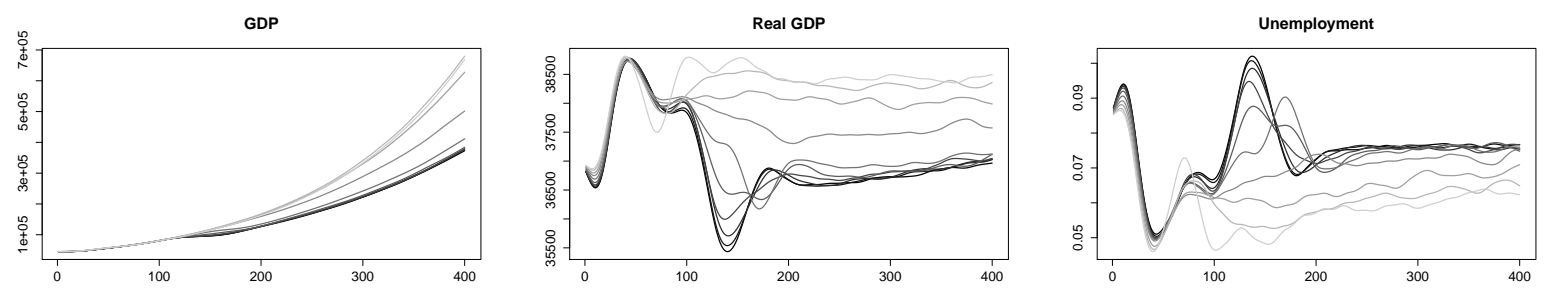

Figure 12: Nominal GDP, real GDP, and unemployment (trends). Lighter gray lines correspond to higher values of the parameter.

As a matter of example, we discursively comment the effects of different risk attitudes by banks in evaluating consumption firms' probability of default, as expressed by the parameter $\varsigma_{c}$ in equation (3.13). The example is useful to stress once again that given the endogenous nature of private money, banks have significantly higher flexibility in extending credit than predicted by the loanable fund approach still employed in the vast majority of DSGE models. Changes in the risk attitude of banks can greatly affect the amount of credit lend to the economy, even when banks are subject to the same institutional constraints.

Figures 12 and 13 show that higher values of risk aversion are associated with higher real output (higher real consumption and moderately lower real investment), lower unemployment, and higher inflation (as reflected by the dynamics of nominal GDP).

The analysis of the dynamics generating these properties is particularly insightful: a more prudent attitude by banks prevents consumption firms from going into excessive debt (figure 13, right) during expansionary phases, lessening in a significant way the amplitude and duration of the recession in the transition. In the three experiments in which the risk aversion parameter is the highest, the economy completely avoids the recession phase experienced in the baseline and low-risk-aversion scenarios.

In these cases the model displays a smooth transition towards the quasi steady-state and tend to converge more rapidly than in low-risk-aversion cases. The prevention of the recession in turn enables the system to attain a balanced growth of prices, wages, profits, investment, GDP, and credit, avoiding the emergence of excessive imbalances in financial flows between different sectors. The economy ends up having more real output and lower unemployment, but also more credit and more inflation than in the baseline, in spite of the fact that firms are individually subjected to stricter credit constraints. ${ }^{47}$

These dynamics highlighted are in line with the main results of the overwhelming stream of literature that has stressed the central role of financial factors and financial institutions in shaping business cycles, starting from the seminal work of Minsky (1986). In particular, the marked recession experienced in the transition under the more risky scenarios and the slower convergence to the quasi-ss are in line with the recent findings of Jorda et al. (2012), showing that more credit-intensive expansions tend to be followed by deeper recessions and slower recoveries.

Although the model is not directly employed for policy analysis in the present paper, the dynamics observed in the baseline and the results of our sensitivity example confirms the topicality of the arguments proposed in order to justify our modelling approach and stress the pivotal importance of the credit creation theory of banking in a macroprudential policy perspective, in line with the recent empirical evidence provided by Werner $(2014,2015)$. These works highlight that the currently prevalent financial intermediation theory of banking, assuming that banks collect deposits and then lend these out, just like other non-bank financial intermediaries, have no empirical foundation. In line with the results of the sensitivity example, Werner (2015) shows that standard theory systematically underestimate banks' flexibility in creating money through credit and throw doubts on capital adequacy and fractional reservebased bank regulation which find their rationale in the loanable funds approach.

analysis of the results suggests that the basic cyclical properties of the model seems to hold for many variables and under the majority of cases investigated. Yet, expectations specifications which allow for big jumps from period to period significantly increase the volatility of macroeconomic variables (in particular in the initial phases), also affecting the shape of the cross-correlation structure of several variables, which appear to be less smooth than in the baseline described here. Obviously these result may be reverted if agents have heterogeneous, endogenously switching, expectations.

${ }^{47}$ Very similar dynamics are obtained for lower values of the parameter $\sigma$, although in this case the mechanism operates on the credit demand side. 

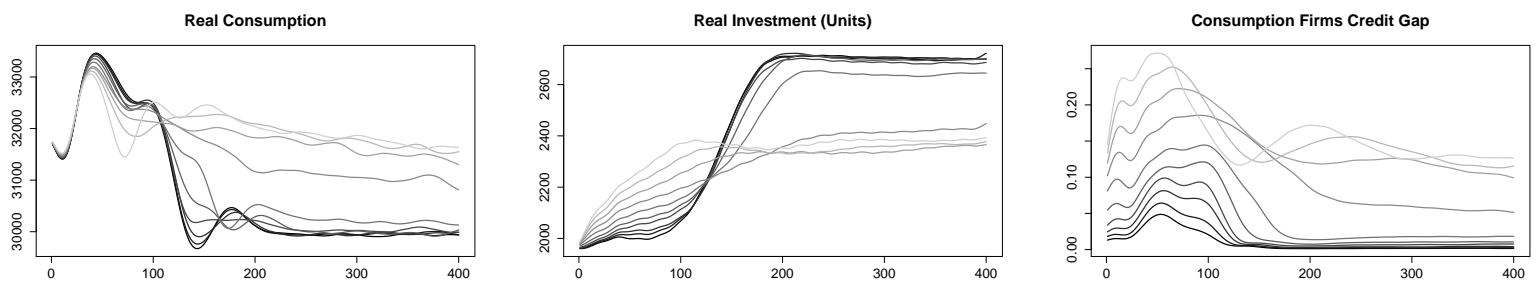

Figure 13: Consumption units, investment units, and share of unsatisfied credit (trends). Lighter gray lines correspond to higher values of the parameter.

\section{Conclusions}

The paper moved from a discussion of the limits of prevailing approaches to macroeconomic modeling. We then discussed the advantages and current limitations of two alternative modeling approaches to macroeconomics, namely the Agent Based and the Stock Flow Consistent frameworks, and we argue in favor of a combination of the two methodologies to be built upon an explicit, realistic, and coherent modeling of individual agents balance sheets and their co-evolution driven by agents' disperse exchanges.

The paper aimed at contributing to this nascent literature in two ways: first, we presented a relatively simple, general and flexible benchmark macroeconomic AB-SFC model to be employed in future works for policy analysis purposes, in particular in the field of bank regulation in a macro-prudential perspective. Second, we present a set of coherent rules and tools to design, calibrate, analyze, and validate AB-SFC models, giving particular attention to the requirement of logical and accounting consistency of these models. Notably, the paper highlights several challenges regarding the calibration of AB-SFC models and proposes a novel approach to solve these issues, thus aiming to shed some light on what appears to be a neglected aspect of the $\mathrm{AB}$ and $\mathrm{AB}-\mathrm{SFC}$ model-building methodologies.

As a preliminary step before the model can be employed for policy analysis, our results have been throughly validated by comparing the cyclical properties of our artificial time series with their empirical counterparts and with several macroeconomic stylized facts highlighted in the literature on business cycles. In addition, we also checked the model ability to match several important microeconomic empirical facts. Our results are very promising, suggesting that the model is able to replicate a significant number of macroeconomic and microeconomic empirical regularities. Sensitivity checks provide some evidence that the cyclical properties of the model hold under different parameterizations.

The analysis of the long term dynamics highlights that, under the majority of cases analyzed, the economy tends to converge to what we defined as a "quasi-SS", which provides the starting point and a benchmark to perform policy analysis in the next works. Results suggest that the interaction of real and financial factors plays a crucial role in driving both short-term business cycles and the long-term evolution of the economic system. Under certain conditions firms and banks may go into excessive investment and credit, which tends to feed financial and real instability affecting the dynamics of the economy also in the long run. Our analysis also confirms that banks are generally far more flexible and less constrained by capital and liquidity requirements than what implied by the loanable funds approach, suggesting that policy macro-prudential prescriptions of standard models may be less effective than usually thought in regulating the banking sector.

The present work is the starting point of a broader research agenda. Although bank regulation either through macro or micro prudential policies, or unconventional policies (e.g. credit and quantitative easing) - represent the natural field of application of the model, the proposed framework is open to several possible developments and integrations. Some of them are already ongoing, such as the introduction of R\&D investment and innovation dynamics in the capital good industry, which would open the possibility for long-term, self-sustained real growth in the model, possibly enhancing the model ability to give account of empirical regularities. The inclusion of households' debt, real estates, income and wealth-dependent consumption behaviors, and proper portfolio functions are further examples of future integrations to the current framework.

\section{References}

Aitchison, J. and Brown, J. A. C. (1957). The Lognormal Distribution with Special Reference to its Use in Economics. Cambridge University Press, New York. 
Amisano, G. and Tristani, O. (2007). Euro area inflation persistence in an estimated nonlinear dsge model. Journal of Economic Dynamics and Control, 34-10:1837-1858.

Andreasen, M. M., Fernández-Villaverde, J., and Rubio-Ramírez, J. (2013). The pruned state-space system for non-linear dsge models: Theory and empirical applications. No. 18983, National Bureau of Economic Research.

Assenza, T., Brock, W., and Hommes, C. (2013a). Animal spirits, heterogeneous expectations and the emergence of booms and busts. Tinbergen Institute Discussion Papers, 205.

Assenza, T., Delli Gatti, D., and Grazzini, J. (2015). Emergent dynamics of a macroeconomic agent based model with capital and credit. Journal of Economic Dynamics and Control, 50:5-28.

Assenza, T., Heemeijer, P., Hommes, C., and Massaro, C. (2013b). Individual expectations and aggregate macro behavior. Tinbergen Institute Discussion Papers, 16.

Axtell, R. (2001). Zipf distribution of u.s. firm sizes. Science, 293-5536:1818-1820.

Barwell, R. and Burrows, O. (2011). Growing fragilities? Balance Sheets in the Great Moderation. Financial Stability Paper 10, Bank of England.

Benes, J., Kumhof, M., and Douglas, L. (2014). Financial crisis in dsge models: a prototype model. IMF Working Paper Series, 14-57:57.

Bernanke, B. and Gertler, M. (1989). Agency costs, net worth, and business fluctuations. American Economic Review, 79-1:1431.

Bils, M. (1987). The cyclical behavior of marginal cost and price. Economic Review, 77-5:838-855.

Bils, M. and Kahn, J. (2000). What inventory behavior tells us about business cycles. American Economic Review, 90-3:458-481.

Borogan Aruoba, S., Bocola, L., and Schorfheide, F. (2013). Assessing dsge model nonlinearities. Technical report, NBER working paper series.

Borogan Aruoba, S., Fernandez-Villaverde, J., and Rubio-Ramirez, J. (2006). Comparing solution methods for dynamic equilibrium economies. Journal of Economic Dynamics \&3 Control, 30.

Bottazzi, G. and Secchi, A. (2003). Common properties and sectoral specificities in the dynamics of u.s. manufacturing companies. Review Of Industrial Organization, 23:217-232.

Brunnermeier, M., Eisenbach, T., and Sannikov, Y. (2012). Macroeconomics with financial frictions: a survey. NBER Working Paper Series, 18102:-.

Brunnermeier, M. and Sannikov, Y. (2014). A macroeconomic model with a financial sector. American Economic Review, 104-2:379-421.

C., L. and Morgan, D. (2006). The credit cycle and the business cycle: New findings using the loan officer opinion survey. Journal of Money, Credit, and Banking, 38-6:15751597.

Cabral, L. M. B. and Mata, J. (2003). On the evolution of the firm size distribution: Facts and theory. American Economic Review, 93-4:1075-1090.

Caiani, A., Godin, A., and Lucarelli, S. (2014). Innovation and finance: a stock flow consistent analysis of great surges of development. Journal of Evolutionary Economics, 24:421-448.

Carlin, W. and Soskice, D. (2015). Macroeconomics: Institutions, Instability, and the Financial System. Oxford University Press.

Caverzasi, E. and Godin, A. (2015). Post-keynesian stock-flow consistent modeling: A survey. Cambridge Journal of Economics, 39(1):157-187.

Cincotti, S., Raberto, M., and Teglio, A. (2010). Credit money and macroeconomic instability in the agent-based model and simulator eurace. Economics - The Open-Access, Open-Assessment E-Journal, 4(26).

Clauset, A., Shalizi, C. R., and Newman, M. E. J. (2009). Power-law distributions in empirical data. SIAM Review, 51:661-703.

Colander, D., Goldberg, M., Haas, A., Juselius, K., Kirman, A., Lux, T., and Sloth, B. (2009). The financial crisis and the systemic failure of the economics profession. Critical Review, 21(2-3):249-267.

Copeland, M. A. (1949). Social Accounting for Moneyflows. The Accounting Review, 24(3):pp. 254-264.

Dawid, H., Gemkow, S., Harting, P., Van der Hoog, S., and Neugart, M. (2012). The eurace@ unibi model: An agent-based macroeconomic model for economic policy analysis.

Dawid, H., Harting, P., and Neugart, M. (2014). Economic convergence: Policy implications from a heterogeneous agent model. Journal of Economic Dynamics \& Control, 44:54-80.

de Masi, G. and Gallegati, M. (2007). Bank-firms topology in italy. Empirical Economics, 43-2:851-866.

Deissenberg, C., Van Der Hoog, S., and Dawid, H. (2008). Eurace: A massively parallel agent-based model of the european economy. Applied Mathematics and Computation, 204-2:541-552.

Delli Gatti, D., Di Guilmi, C., Gaffeo, E., Giulioni, G., Gallegati, M., and Palestrini, A. (2005). A new approach to business fluctuations: heterogeneous interacting agents, scaling laws and financial fragility. Journal of Economic Behavior $\varepsilon_{3}$ Organization, 56:489-512.

Delli Gatti, D., Di Guilmi, C., Gallegati, M., and Gaffeo, E. (2004). Bankruptcy as an exit mechanism for systems with a variable number of components. Physica A: Statistical Mechanics and its Applications., 344:8-13.

Delli Gatti, D., Gaffeo, E., and Gallegati, M. (2010a). Complex Agent-Based Macroeconomics: a Manifesto for a New Paradigm. Journal of Economic Interaction and Coordination, 5-2:111-135.

Delli Gatti, D., Gaffeo, E., Gallegati, M., Giulioni, G., and Palestrini, A. (2008). Emergent Mcroeconomics. An AB Approach to Business Fluctutations. Springer. 
Delli Gatti, D., Gallegati, M., Greenwald, B. C., Russo, A., and Stiglitz, J. E. (2010b). The financial accelerator in an evolving credit network. Journal of Economic Dynamics 8 Control, 34:1627-1650.

Di Guilmi, C., Gallegati, M., and Ormerod, P. (2004). Scaling invariant distributions of firms exit in oecd countries. Physica A: Statistical and Theoretical Physics, 334:267-273.

Dosi, G., Fagiolo, G., Napoletano, M., and Roventini, A. (2012). Wage formation, investment behavior and growth regimes: An agent-based analysis. Revue de l'OFCE, 0-5:235-261.

Dosi, G., Fagiolo, G., Napoletano, M., and Roventini, A. (2013). Income distribution, credit and fiscal policies in an agent-based keynesian model. Journal of Economic Dynamics and Control, 37-8:1598-1625.

Dosi, G., Fagiolo, G., Napoletano, M., Roventini, A., and Treibich, T. (2015). Fiscal and monetary policies in complex evolving economies. Journal of Economic Dynamics and Control, 52:166-189.

Dosi, G., Fagiolo, G., and Roventini, A. (2006). Animal spirits, lumpy investment, and endogenous business cycles. LEM Working Paper Series, 2005-4.

Dosi, G., Fagiolo, G., and Roventini, A. (2010). Schumpeter Meeting Keynes: A Policy-Friendly Model of Endogenous Growth and Business Cycles. Journal of Economic Dynamics and Control, 34(9):1748-1767.

Eichner, A. S. (1976). The Megacorp and Oligopoly: Micro Foundations of Macro Dynamics. Cambridge University Press.

Esptein, J. (2006). Remarks on the Foundations of Agent-Based Generative Social Science. In Tesfatsion, L. and Judd, K., editors, Handbook of Computational Economics Vol.2, pages 1585-1602. North Holland, Amsterdam.

Fagiolo, G., Napoletano, M., and Roventini, A. (2008). Are output growth-rate distribution fat-tailed? some evidence from oecd countires. Journal of Applied Econometrics, 23:639-669.

Fagiolo, G. and Roventini, A. (2012). Macroeconomic policy in dsge and agent-based models. Inet Research Note, -(6):- .

Farmer, J. and Foley, D. (2009). The economy needs agent-based modelling. Nature, 460(7256):685-686.

Fazzari, S., Hubbard, R., and Petersen, B. (1988). Financing Constraints and Corporate Investment. Brookings Papers on Economic Activity, 1:141-195.

Gaffeo, E., Gallegati, M., and Palestrini, A. (2003). On the size distribution of firms: additional evidence from the g7 countries. Physica A: Statistical Mechanics and its Application, 324-1:117-123.

Godley, W. (1997). Macroeconomics without Equilibrium or Disequilibrium. Working Paper Series 205, The Levy Economic Institute of Bard College.

Godley, W. and Cripps, F. (1983). Macroeconomics. Oxford University Press.

Godley, W. and Lavoie, M. (2007). Monetary Economics An Integrated Approach to Credit, Money, Income, Production and Wealth. Palgrave MacMillan, New York.

Godley, W. and Wray, L. R. (1999). Can goldilocks survive? Technical report, The Levy Economic Institute of Bard College.

Godley, W. and Zezza, G. (2006). Debt and lending: A cri de coeur. Technical report, Levy Institute at Bard College.

Greenwald, B. C. and Stiglitz, J. E. (1993). Financial market imperfections and business cycles. The Quarterly Journal of Economics, 108(1):77-114.

Halling, M., Yu, J., and Zechner, J. (2012). Leverage dynamics over the business cycle. AFA 2012 Chicago Meetings Paper, $-:-$

Jakab, Z. and Kumh (2014). Models of banking: Loanable funds or loans that create funds? IMF Working Paper Series.

Jakab, Z. and Kumhof, M. (2015). Banks are not intermediaries of loanable funds - and why this matters. Bank of England Working Paper Series, 529.

Jorda, O., Schularick, M., and Taylor, A. (2012). When credit bites back: Leverage, business cycles, and crises. Federal Reserve Bank of San Francisco Working Paper Series, 2011-27:42.

Kinsella, S. (2011). Words to the wise: Stock flow consistent modeling of financial instability. Available at SSRN 1955613.

Kinsella, S., Greiff, M., and Nell, E. J. (2011). Income Distribution in a Stock-Flow Consistent Model with Education and Technological Change. Eastern Economic Journal, 37:134-149.

Kiyotaki, N. and Moore, J. (1997). Credit cycles. Journal of Political Economy, 105-2:211-248.

Klenow, P. and Kryvtsov, O. (2005). State-dependent or time-dependent pricing: does it matter for recent u.s. inflation? NBER Working Paper Series, 11043:54.

Lavoie, M. (1992). Foundations of Post-Keynesian Economic Analysis. Edward Elgar, Aldershot.

Lavoie, M. (2015). Post-Keynesian Economics: New Foundations. Edward Elgar.

Leary, M. (2009). Bank loan supply, lender choice, and corporate capital structure. The Journal of Finance, 64-3:11431185.

Levy, M. and Solomon, S. (1996). Power laws are logarithmic Boltzmann laws. International Journal of Modern Physics $C, 7: 595-601$.

Lux, T. (2014). A model of the topology of the bank-firm credit network and its role as channel of contagion. Kiel Institute Working Paper Series, 1950.

McLeay, M., Radia, A., and Thomas, R. (2014). Money creation in the modern economy. Bank of England Quarterly Bulletin, Q1:14.

Meyers, S. (1984). Capital Structure Puzzle. Journal of Finance, 39-3:575-592.

Minsky, H. P. (1986). Stabilizing an unstable economy. Yale University Press, New Haven.

Nirei, M. and Souma, W. (2004). Income distribution and stochastic multiplicative process with reset event. In Gallegati, M., Kirman, A., and Marsili, M., editors, The Complex Dynamics of Economic Interaction, Essays in Economics and Econophysics. Springer. 
Nuño, G. and Thomas, C. (2013). Bank leverage cycles. ECB Working Paper Series, 1524.

Quadrini, V. (2011). Macroeconomic fluctuations. Federal Reserve Bank of Richmond Economic Quarterly, 97-3:209254.

Raberto, M., Teglio, A., and Cincotti, S. (2012). Debt, deleveraging and business cycles: An agent-based perspective. Economics - The Open-Access, Open-Assessment E-Journal, 27:50.

Riccetti, L., Russo, A., and Gallegati, M. (2013). Leveraged network-based financial accelerator. Journal of Economic Dynamics and Control, 37-8:1626-1640.

Riccetti, L., Russo, A., and Gallegati, M. (2014). An agent-based decentralized matching macroeconomic model. Journal of Economic Interaction and Coordination, 3:-.

Rotemberg, J. and Woodford, M. (1999). The cyclical behavior of prices and costs. NBER Working Paper Series, 6909.

Rubio-Ramirez, J. and Fernandez-Villaverde, J. (2004). Estimating dynamic equilibrium economies: linear versus nonlinear likelihood. Journal of Applied Econometrics, 20-7:891-910.

Sahota, G. S. (1978). Theories of personal income distribution: A survey. Journal of Economic Literature, 16:1-55.

Salle, I., Y?ld?zoglu, M., and Senegas, M. (2013). Inflation targeting in a learning economy: An abm perspective. Economic Modelling, 34:114-128.

Saviotti, P. P. and Pyka, A. (2004). Economic development by the creation of new sectors. Journal of evolutionary economics, 14(1):1-35.

Seppecher, P. (2012). Monnaie Endogène et Agents Hétérogènes dans un Modèle Stock-Flux Cohérent. In Political economy and the Outlook for Capitalism, Paris (France).

Shaikh, A. (1974). Laws od production and laws of algebra: The humbug production function. The Review of Economics and Statistics, 1:115-120.

Simon, H. (1976). From Substantive to Procedural Rationality. In Latsis, S., editor, Method and Appraisal in Economics, pages 129-148. Cambridge University Press, Cambridge UK.

Spence, A. (1977). Entry, capacity, investment and oligopolistic pricing. The Bell Journal of Economics, 8-2:534-544.

Stanley, M., Buldyrev, S., Havhn, S., Mantegna, R., Salinger, M., and Stanley, E. (1995). Zipf plots and the size distribution of firms. Economic Letters, 49:453-457.

Steindl, J. (1952). Maturity and Stagnation in American Capitalism. Blackwell.

van der Hoog, S. and Dawid, H. (2015). Bubbles, crashes and the financial cycle: Insights from a stock-flow consistent agent-based macroeconomic model. Working Papers in Economics and Management-University of Bielefeld, 1-2015:58.

Verspagen, B. (2002). Evolutionary macroeconomics: A synthesis between neo-schumpeterian and post-keynesian lines of thought. The Electronic Journal of Evolutionary Modeling and Economic Dynamics, 1007.

Waters, G. (2013). Quantity versus price rationing of credit: An empirical test. International Journal of Financial Studies, 1-3:45-53.

Werner, R. (2014). Can banks individually create money out of nothing? - the theories and the empirical evidence. International Review of Financial Analysis, 36:1-19.

Werner, R. (2015). A lost century in economics: Three theories of banking and the conclusive evidence. International Review of Financial Analysis, forthcoming.

Zietz, J. (2008). A clarifying note on converting to log-deviations from the steady state. Economics Bulletin, 3-50:1-15. 


\section{A Baseline Calibration}

As explained in section 4 our procedure is based on the imposition of a real stationary state coupled with a nominal steady state growth (i.e. inflation) at the macroeconomic level. More precisely, we first declare a set of exogenous parameters, aggregate variables, and stock-flow norms that we fix at reasonable values (see section A.4). Then we employ the accounting identities and the steady state (SS hereafter) conditions to find a numerical solution to the system.

For tractability and explanatory reasons we divided the SS system of equations in three sub-systems: the first block contains the equations which refer to capital good producers (section A.1), the second presents the set of equations related to consumption firms (section A.2), and the third (section A.3) refers to households, banks and the public sector (government and central bank). Once the first block of the system is solved, its solution are employed to solve the second sub-system, whose solutions in turn are used to solve the third one.

\section{A.1 Capital firms SS relations}

In the equations, letters in bold type indicate the dependent variables of the system. All other variables and parameter values are set exogenously to characterize numerically the SS.

The first block is a system of ten equations in ten unknowns referring to capital firms and, indirectly, to banks, as far as loans and deposits in the capital sector balance sheet are concerned. Equation A.1 states that workers employed in the capital sector $N_{k}$ should be equal to the real output of capital firms $y_{k}$ divided by labor productivity $\mu_{N}$. Prices of capital goods $p_{k}$ (eq. A.3) are a markup $m u_{k}$ over unit (variable) costs, which are equal to wages $W$ over labor productivity (eq. A.2). Capital firms want to hold an amount of deposits $D_{k}$ equal to a fraction sigma of wages paid to workers (eq. A.4). Since we have stationary state in real terms, capital firms' real output is exactly equal to replacement investment realized by consumption firms' $i_{c}$ in order to replace obsolete capital. This in turn is equal to total real capital $k$ over real capital duration $\kappa$ (eq. A.5). Real capital inventories (eq. A.6) are constant and equal to a share $\nu$ of real output (i.e. sales). Profits of capital firms are revenues from sales plus interests on previous period deposits, plus the variation of nominal inventories (evaluated at their unit costs of production $u c_{k}$ ), minus wages and interests paid on the previous-period stock of loans (eq. A.7). Notice that past period values of nominal variables will be equal to the current value divided by $\left(1+g_{S S}\right), g_{S S}$ being the exogenously imposed SS nominal rate of growth. A fraction $\tau_{k}$ of profits goes to pay taxes (eq. A.8), while a share $\rho_{k}$ of remaining net profits is distributed as dividends to households (eq. A.9). Finally, for accounting reasons the variation of loans (eq. A.10) should be equal to the sum of the variation in the nominal value of inventories and the variation of deposits, minus retained earnings (see the KA column for the capital sector in the Transaction Flow Matrix presented in appendix A).

$$
\begin{aligned}
N_{k} & =\frac{\mathbf{y}_{\mathbf{k}}}{\boldsymbol{\mu}_{\mathbf{N}}} \\
\mathbf{u} \mathbf{c}_{\mathbf{k}} & =\frac{W N_{k}}{\mathbf{y}_{\mathbf{k}}}=\frac{W}{\boldsymbol{\mu}_{\mathbf{N}}} \\
\mathbf{p}_{\mathbf{k}} & =\left(1+m u_{k}\right) \mathbf{u} \mathbf{c}_{\mathbf{k}} \\
\mathbf{D}_{\mathbf{k}} & =\sigma W N_{k} \\
\mathbf{y}_{\mathbf{k}} & =\left(i_{c}=\right) \frac{k}{\kappa} \\
\mathbf{i n v}_{\mathbf{k}} & =\nu \mathbf{y}_{\mathbf{k}} \\
\boldsymbol{\pi}_{\mathbf{k}} & =\mathbf{p}_{\mathbf{k}} \mathbf{y}_{\mathbf{k}}+\frac{i^{d} \mathbf{D}_{\mathbf{k}}}{1+g_{S S}}+\mathbf{i n v}_{\mathbf{k}} \frac{g_{S S}}{1+g_{S S}} \mathbf{u c}_{\mathbf{k}}-W N_{k}-\frac{i^{l} \mathbf{L}_{\mathbf{k}}}{1+g_{S S}} \\
\mathbf{T}_{\mathbf{k}} & =\boldsymbol{\pi}_{\mathbf{k}} \tau_{k} \\
\mathbf{D i} \mathbf{v}_{\mathbf{k}} & =\rho_{k}\left[\boldsymbol{\pi}_{\mathbf{k}}\left(1-\tau_{k}\right)\right] \\
\mathbf{g}_{S S} & =\left(\mathbf{i n v}_{\mathbf{k}} \frac{g_{S S}}{1+g_{S S}} \mathbf{u c} \mathbf{c}_{\mathbf{k}}\right)+\left(\mathbf{D}_{\mathbf{k}} \frac{g_{S S}}{1+g_{S S}}\right)-\left(\boldsymbol{\pi}_{\mathbf{k}}-\mathbf{T}_{\mathbf{k}}-\mathbf{D i v}_{\mathbf{k}}\right)
\end{aligned}
$$

\section{A.2 Consumption firms SS relations}

The second block of equations refers to consumption firms. Workers employed in the consumption sector are computed by dividing output for labor productivity in the consumption sector (eq. A.11). By 
definition, labor productivity in the case of a technology which employs labor and capital fixed coefficients is equal to the product of capital productivity $\mu_{k}$ and the fixed capital-labor ratio $l_{K}$. Prices are a markup $m u_{c}$ over unit variable costs (eq. A.15), defined as wages paid to workers over output (eq. A.12). Unit costs are computed as overall production costs, including the financial amortization of capital, divided by output (eq. A.13). Since we are in a real stationary state and given the assumption that capital lasts for $\kappa$ periods, consumption firms invest in each period to buy an amount of $k / \kappa$ capital goods in order to replace the batch of obsolete capital (purchased $\kappa$ periods ahead) thus keeping the total stock of capital $k$ constant. Since we further assume a linear financial amortization of capital, consumption firms register an amortization cost equal to a share $1 / \kappa$ of the disbursement originally incurred to buy each batch of capital. This disbursement was equal to $\frac{k}{\kappa} \frac{p_{k}}{\left(1+g_{S S}\right)^{t}}$ for each batch purchased $t=1, \ldots, \kappa$ periods ahead. Therefore amortization costs are equal to $\frac{p_{k} k}{\kappa^{2}} \sum_{\kappa}^{j=1} \frac{1}{\left(1+g_{S S}\right)^{3}}$. Following the same reasoning, we can determine the nominal value of the stock of capital held by consumption firms $K_{c}$ as expressed by equation A.14. Consumption firms want to hold a share $\sigma$ of wages as deposits (eq. A.16). Output is given by the stock of capital multiplied by the rate of capacity utilization $u$ and by the productivity of capital (eq. A.17). Real inventories are a share of real sales, which in the SS are equal to output (eq. A.18). Profits in the case of consumption good producers differ from those of capital firms, as they also include the amortization cost of previously purchased capital batches (eq. A.19). Taxes and dividends are then defined as in the case of capital good producers (eq. A.20 and eq. A.21). The variation of loans granted to consumption firms can be obtained by exploiting the capital account identity (see column KA for the consumption sector in the Transaction Flow Matrix presented in appendix A) for the consumption sector. The difference with respect to the correspondent equation for capital firms is the inclusion of the investment and amortization flows (eq. A.22).

$$
\begin{aligned}
& N_{c}=\frac{\mathbf{y}_{\mathbf{c}}}{\mu_{K} \mathbf{l}_{\mathbf{K}}} \\
& \mathbf{u v c}_{\mathbf{c}}=\frac{W N_{c}}{\mathbf{y}_{\mathbf{c}}} \\
& \mathbf{u c}_{\mathbf{c}}=\frac{W N_{c}+\frac{p_{k} k}{\kappa^{2}} \sum_{j=1}^{\kappa} \frac{1}{\left(1+g_{S S}\right)^{j}}}{\mathbf{y}_{\mathbf{c}}} \\
& \mathbf{K}_{\mathbf{c}}=\frac{p_{k} k}{\kappa^{2}} \sum_{j=1}^{\kappa} \frac{j}{\left(1+g_{S S}\right)^{C L-j}} \\
& \mathbf{p}_{\mathbf{c}}=\left(1+m u_{c}\right) \mathbf{u v c}_{\mathbf{c}} \\
& \mathbf{D}_{\mathbf{c}}=\sigma W N_{c} \\
& \mathbf{y}_{\mathbf{c}}=k u \mu_{K} \\
& \operatorname{inv}_{\mathbf{c}}=\nu \mathbf{y}_{\mathbf{c}} \\
& \boldsymbol{\pi}_{\mathbf{c}}=\mathbf{p}_{\mathbf{c}} \mathbf{y}_{\mathbf{c}}+\frac{i^{d} \mathbf{D}_{\mathbf{c}}}{1+g_{S S}}+\mathbf{i n v}_{\mathbf{c}} \frac{g_{S S}}{1+g_{S S}} \mathbf{u c}_{\mathbf{c}}-W N_{c}-\frac{i^{l} \mathbf{L}_{\mathbf{c}}}{1+g_{S S}}-\frac{p_{k} k}{\kappa^{2}} \sum_{j=1}^{\kappa} \frac{1}{\left(1+g_{S S}\right)^{j}} \\
& \mathbf{T}_{\mathbf{c}}=\boldsymbol{\pi}_{\mathbf{c}} \tau_{c} \\
& \operatorname{Div}_{\mathbf{c}}=\rho_{c}\left[\boldsymbol{\pi}_{\mathbf{c}}\left(1-\tau_{c}\right)\right] \\
& \mathbf{L}_{\mathbf{c}}\left(\frac{g_{S S}}{1+g_{S S}}\right)=\left(i_{c} p_{k}\right)\left(\mathbf{i n v}_{\mathbf{c}} \frac{g_{S S}}{1+g_{S S}} \mathbf{u c}_{\mathbf{c}}\right)+\left(\mathbf{D}_{\mathbf{c}} \frac{g_{S S}}{1+g_{S S}}\right)-\left(\boldsymbol{\pi}_{\mathbf{c}}-\mathbf{T}_{\mathbf{c}}-\mathbf{D i v}_{\mathbf{c}}\right)-\frac{p_{k} k}{\kappa^{2}} \sum_{j=1}^{\kappa} \frac{1}{\left(1+g_{S S}\right)^{j}}
\end{aligned}
$$

The second block thus presents a system of twelve equations in twelve unknowns, where bold letters indicate dependent variables, as usual. Notice that variables referring to capital firms, such as $p_{k}$ or $\nu_{k}$, are no longer indicated as dependent variables, as their value was already computed in the first block of the SS system of equation.

\section{A.3 The rest of the economy}

The third block of equations encompasses the relations referring to the households and banking sectors, plus those related to the public sector which is composed of the general government and the central bank.

Total employment is given by the sum of workers hired by the consumption, capital, and public sectors (eq. A.23). Households' income is composed of wages, interests on deposits, dividends and the tax-exent 
dole $\omega W$ that unemployed workers receive from the government. Dividends are distributed by firms and bank to households at the end of the period, after households have consumed and firms and banks have paid taxes. Therefore, we assume that dividends from period $t-1$ enter in the (behavioral) definition of the gross income of households of period $t$ (although they have already increased the amount of deposits held by households in period t-1, see equation ...) Net income is then defined by equation A.24, whereas taxes paid by households are given by equation A.25. Real consumption is a function of real net income and the real net-wealth inherited from the previous period (eq. A.26). Given the stationary state condition real consumption is exactly equal to the amount of goods produced by consumption firms (eq. A.27). Nominal consumption is obtained by multiplying real consumption for the price of consumption good (eq. A.28). The variation of households' net worth obviously depends on the difference between net-income, as defined above, and consumption. However, since the definition of net income given above includes a the flow of dividends paid at the end of the previous period (thus already increasing households' net worth), while neglecting current period dividends, we respectively subtract and add them in the equation to get the right dynamics for households' net worth (eq. A.29). Households' net wealth takes the form of banks' deposits (eq. A.30).

$$
\begin{aligned}
& \mathbf{N}_{\text {tot }}=N_{c}+N_{k}+\mathbf{N}_{\mathrm{g}} \\
& \mathbf{N I}_{\mathbf{h}}=\left(W \mathbf{N}_{\text {tot }}+\frac{i^{d} \mathbf{D}_{\mathbf{h}}}{1+g_{S S}}+\frac{D i v_{c}+D i v_{k}+\mathbf{D i v}_{\mathbf{b}}}{1+g_{S S}}\right)\left(1-\tau_{h}\right)-\omega W\left(\operatorname{size}_{\Phi_{H}}-\mathbf{N}_{\text {tot }}\right) \\
& \mathbf{T}_{\mathbf{h}}=\left(W \mathbf{N}_{\text {tot }}+\frac{i^{d} \mathbf{D}_{\mathbf{h}}}{1+g_{S S}}+\left(\frac{D i v_{c}+D i v_{k}+\mathbf{D i v}_{\mathbf{b}}}{1+g_{S S}}\right) \tau_{h}\right. \\
& \mathbf{c}_{\mathbf{h}}=\boldsymbol{\alpha}_{\mathbf{1}} \frac{\mathbf{N I}_{\mathbf{h}}}{p_{c}}+\alpha_{2} \frac{\mathbf{N W}_{\mathbf{h}}}{\left(1+g_{s s}\right) p_{c}} \\
& \mathbf{c}_{\mathbf{h}}=y_{c} \\
& \mathbf{C}_{\mathbf{h}}=\mathbf{c}_{\mathbf{h}} p_{c} \\
& \mathbf{N W}_{\mathbf{h}}\left(\frac{g_{S S}}{1+g_{S S}}\right)=\mathbf{N I}_{\mathbf{h}}-\mathbf{C}_{\mathbf{h}}-\frac{\left(D i v_{c}+D i v_{k}+\mathbf{D i v}_{\mathbf{b}}\right)}{1+g_{S S}}+\left(D i v_{c}+D i v_{k}+\mathbf{D i v}_{\mathbf{b}}\right) \\
& \mathbf{N W}_{\mathbf{h}}=\mathbf{D}_{\mathbf{h}}
\end{aligned}
$$

Profits by banks are the sum of interests on the previous period outstanding stock of loans, plus interests paid by the government on the stock of bonds held by banks, minus interests paid on deposits of households and firms (eq. A.22). ${ }^{48}$ Banks pay taxes (eq. A.32) and distribute a share of net-profits to households (eq. A.33). Banks' net worth is defined as the difference between assets, that is loans, bonds, and reserves, and liabilities, which are represented by customers' deposits (eq. A.34). Given the structure of the economy banks reserves (eq. A.35) are exactly equal to central bank's holdings of government bonds (see the Balance Sheet Matrix of the economy presented in the appendix A), which are defined as the a residual (eq. A.36).

The variation of government debt is given by the difference between government outlays for wages of public servants, unemployment benefits and interests on past period public debt, and government revenues from taxes and central bank's profits (eq. A.37). This latter are just represented by interest on bonds held by the central bank, which are promptly returned to the government (eq. A.38).

\footnotetext{
${ }^{48}$ We assume cash advances by the $\mathrm{CB}$ to be equal to zero as banks' in the SS have enough liquidity to satisfy the mandatory liquidity ratio.
} 


$$
\begin{aligned}
\boldsymbol{\pi}_{\mathbf{b}} & =i^{l} \frac{L_{c}+L_{k}}{1+g_{S S}}+i^{b} \frac{\mathbf{B}_{\mathbf{b}}}{1+g_{S S}}-i^{d} \frac{\mathbf{D}_{\mathbf{h}}+D_{c}+D_{k}}{1+g_{S S}} \\
\mathbf{T}_{\mathbf{b}} & =\boldsymbol{\pi}_{\mathbf{b}} \tau_{b} \\
\mathbf{D i v}_{\mathbf{b}} & =\rho_{b}\left[\boldsymbol{\pi}_{\mathbf{b}}\left(1-\tau_{b}\right)\right] \\
\mathbf{N W}_{\mathbf{b}} & =L_{c}+L_{k}+\mathbf{B}_{\mathbf{b}}+\mathbf{R}_{\mathbf{b}}-\mathbf{D}_{\mathbf{h}}-D_{c}-D_{k} \\
\mathbf{R}_{\mathbf{b}} & =\mathbf{B}_{\mathbf{C B}} \\
\mathbf{B}_{\mathbf{C B}} & =\mathbf{B}-\mathbf{B}_{\mathbf{b}} \\
\mathbf{B}\left(\frac{g_{S S}}{1+g_{S S}}\right) & =W \mathbf{N}_{\mathbf{g}}+\omega W\left(s i z e_{\Phi_{H}}-\mathbf{N}_{\mathbf{t o t}}\right)+\frac{i^{b} \mathbf{B}}{1+g_{S S}}-\left(\mathbf{T}_{\mathbf{h}}+\mathbf{T}_{\mathbf{b}}+T_{c}+T_{k}\right)-\boldsymbol{\pi}_{\mathbf{C B}} \\
\pi_{\mathbf{C B}} & =\frac{i^{b} \mathbf{B}_{\mathbf{C B}}}{1+g_{S S}}
\end{aligned}
$$

\section{A.4 Exogenous variables set-up}

The last block is characterized by sixteen equations and eighteen unknowns. We close the system by adding two further equations. Equation A.39 states that in the SS the unemployment rate is equal to $u=0.08$. Equation A.40 is to ensure that the banking sector has a reasonable level of net worth in the $\mathrm{SS}$, thereby assuming that this is equal to a share $\beta=0.08$ of its assets:

$$
\begin{aligned}
u & =\frac{{\text { size } e_{H}}_{\mathbf{N}_{\mathrm{tot}}} \mathbf{N}_{\mathrm{tot}}}{\mathbf{N}_{\mathrm{tot}}} \\
\mathbf{N W}_{\mathbf{b}} & =\beta\left(L_{c}+L_{k}+\mathbf{B}_{\mathbf{b}}+\mathbf{R}_{\mathbf{b}}\right)
\end{aligned}
$$

In order to find a numerical solution for the steady state we have to set exogenously the values of some variables. First we set the desired rate of inflation $g_{S S}$ to 0.0075 . The population of households is composed of 8000 agents. Given that the number of capital firms is $1 / 5$ of the number of consumption firms we set the number of workers initially employed in capital and consumption sectors to 1000 and 5000 respectively, so that each firm, regardless its type, starts with 25 employees. We further assume an unemployment rate of $u=8 \%$ and we set wages $W=5$.

We then set the SS amount of capital goods $k=40000$ and we set for simplicity their productivity to 1 and their duration $\kappa=20$. Since we want to start with a reasonable rate of capacity utilization by consumption firms we set the SS value of $u=0.8$.

Both types of firms holds an amount of inventories equal to a share $\nu=0.1$ of real sales.

We set the markup for capital firms equal to 0.075 . Since consumption firms have to invest in capital goods their markup over variable unit costs should be higher than capital firms'. We set $m u_{c}=0.319$ which corresponds to a mark up over total unit costs (including capital amortization costs) of 0.1 , in order to characterize consumption firms' with an adequate margin of profits in the initial period of the simulation.

We assume the rate of taxation to be equal across sectors $\tau_{h}=\tau_{b}=\tau_{c}=\tau_{k}=0.18$.

Consumption and capital firms distribute a share equal to $\rho_{c}=\rho_{k}=0.9$ of their after tax profits to households, while dividends for banks are a share $\rho_{b}=0.6$ of net profits. Both types of firms hold a share $\sigma=1$ of their past period expenditure on wages for precautionary reasons.

Firms' pay an interest $i^{l}=0.0075$ to banks. The interest rate on deposits $i^{d}$ is set to 0.0025 . The interest rate on bonds $i^{b}$ is set equal to 0.0025 as well.

Having specified this exogenous values, the SS system of equation can be solved numerically in order to obtain the initial values for stocks and flows displayed in the accounting matrices presented in Appendix A.

Real and financial stocks are then distributed uniformly across agents within each sector. For real capital, deposits, inventories, bonds and reserves - which have either a 1-period or indefinite duration this can be done by simply divide the aggregate stock value for the number of agents in the sector.

The procedure is relatively more complicated for loans and capital goods, which are subjected to a financial amortization schedule over $\eta$ and $\kappa$ periods, respectively.

As explained in section 4 the outstanding values of the collection of heterogeneous loans that firms hold in their balance sheet have to sum up to $L_{c}$. Similarly the nominal values of the different batches of capital goods held by consumption firms have to sum up to $K_{c}$. 
In order to characterize each stock of loans, we first distribute loans uniformly across firms within each sector and indicate by $L_{x}^{T o t}=\frac{L_{x}}{s i z e_{\Phi_{k}}}$ the total debt level of the individual firm $x$. Then, knowing the steady state rate of inflation $g_{S S}$, and the loan repayment schedule, we solve the following system of equations to compute the outstanding value $L_{j}$ of each loan granted in period $-j$ for an original amount $L_{x j}^{*}$.

$$
L_{x j}^{*}=L_{x, j-1}^{*}\left(1+g_{s s}\right) \quad \& \quad L_{x j}=L_{x j}^{*} \frac{\eta-j}{\eta} \quad \& \quad L_{x}^{T o t}=\sum_{i=0}^{\eta-1} L_{x j}
$$

More precisely, $L_{x 0}$ (i.e. the value of the loan granted in period 0 to firm $x$ ), will be given by:

$$
L_{x 0}=\frac{L_{x}^{T o t}}{\sum_{j=0}^{\eta-1}\left(\frac{\eta-j}{\eta} \frac{1}{(1+g r)^{j}}\right.}
$$

We can then compute $L_{x j}^{*}=L_{x 0} /(1+g r)^{j}$ for each loan indexed by $j=0, \eta-1$. Finally, we use $L_{x j}=L_{x j}^{*} \frac{\eta-j}{\eta}$ to compute their outstanding values, as recorded in the begin-of-simulation-period firm's balance sheet.

Similarly, knowing the nominal value of consumption firms' capital stock, the inflation rate $g_{S S}$, and the amortization schedule, we derive the nominal value for each capital batch owned by consumption firms' as:

$$
K_{j}=\frac{p_{k}}{\left(1+g_{s s}\right)^{j}} k \frac{\kappa-j}{\kappa},
$$

The above procedure allows to characterize firms' initial balance sheets. Indirectly, it also allows to characterize the balance sheets of banks since every single loan recorded on the liability side of a firm's balance sheet is also recorded on the asset side of a bank's balance sheet. This credit relations linking firms to banks and vice-versa are drawn randomly, although we distribute them in a way such that each bank has the same number of loans, for a same amount, and with similar maturities, with the same number of customers.

The numerical solution of the steady state also provides the values for some parameters of the model, namely $\alpha_{1}$, the propensity to consume out of income, $\nu_{N}$, the productivity of labor in the capital sector. The SS-values are also employed to set the values of other behavioral parameters which do not directly enter in the system of equation describing the SS: $\bar{u}, \bar{r}$ the target capacity utilization and profits rates in consumption firms' investment function and $C R_{0}^{T}, L R_{0}^{T}$, banks' initial target capital and liquidity ratios, are set equal to their correspondent values in the $\mathrm{SS}$ :

$$
\begin{aligned}
\bar{u} & =0.8 \\
\bar{r} & =\frac{O C F_{c}}{K_{c}} \\
O C F_{c} & =\pi_{c}\left(1-\tau_{c}\right)+\frac{p_{k} k}{\kappa^{2}} \sum_{\kappa}^{j=1} \frac{1}{\left(1+g_{S S}\right)^{j}}-i n v_{c} \frac{g_{S S}}{1+g_{S S}} u c_{c}-L_{0 c} \frac{1}{\eta} \sum_{j=1}^{\eta} \frac{1}{\left(1+g_{S S}\right)^{j}} \\
C R_{0}^{T} & =\frac{N W_{b}}{L_{c}+L_{k}}, L R_{0}^{T} \\
L R_{0}^{T} & =\frac{R_{b}}{D_{h}+D_{c}+D_{k}}
\end{aligned}
$$

where the operating cash flows can be derived from net-profits by adding amortization costs and subtracting the nominal variation of inventories and principal repayment over previous debt (eq. A.46).

Banks' risk aversion parameters $\varsigma_{k}$ and $\varsigma_{c}$ were computed in order to have a single-period probability of default $\mathrm{pr}^{D}=1 \%$, at the steady state levels of operating cash flow and debt service costs. ${ }^{49}$ Solving for $\varsigma$ equation 3.13, we obtain:

$$
\begin{aligned}
\varsigma_{k} & =\frac{O C F_{k}}{L_{0 k} i^{l}+\frac{L_{0 k}}{\eta}}-\ln \left(\frac{1}{p r^{D}}-1\right) \\
\varsigma_{c} & =\frac{O C F_{c}}{L_{0 c} i^{l}+\frac{L 0 c}{\eta}}-\ln \left(\frac{1}{p r^{D}}-1\right)
\end{aligned}
$$

${ }^{49}$ Notice that this value represents the borrower's probability of default estimated by banks for each period from when the loan is granted to its complete repayment. The estimated overall probability of having a default before the loan is repaid is higher. 
where $O C F_{k}=\pi_{k}\left(1-\tau_{k}\right)-i n v_{k} \frac{g_{S S}}{1+g_{S S}} u c_{k}-L 0_{0 k} \frac{1}{\eta} \sum_{j=1}^{\eta} \frac{1}{\left(1+g_{S S}\right)^{3}}$.

Remaining free parameters of the model were set as follows: The $\gamma_{1} \gamma_{2}$, the profit and capacity utilization rates weights, were set respectively equal to 0.01 and $0.02 . \epsilon^{d}=\epsilon^{l}$ and $\epsilon^{c}=\epsilon^{k}$, the parameters affecting the probability of switching to a new supplier, were set so that a $15 \%$ and $20 \%$ difference between the prices of the old and new suppliers gives a probability of $50 \%$ to switch. The parameters of the Folded Normal Distribution used in the prices, wages, and interest adaptive strategies, $\left(\mu_{F N}, \sigma_{F N}^{2}\right)$, were set so that the expected value of a sample is 0.0075 . Finally, the number of potential partners on consumption and capital good markets $\chi_{c}, \chi_{k}$ were both set equal to 5 , The number of potential partners on deposit and credit markets $\chi_{d}, \chi_{l}$ were set equal to 3 , and the numer of potential partners on the labor market $c h i_{n}$ was set equal to 10 .

\section{B Parameters values and Initial Setup}

\begin{tabular}{|l|c|c|c|c|c|c|c|}
\hline & Households & Cons. Firms & Cap. Firms & Banks & Govt. & Central Bank & Total \\
\hline Deposits & +80704.1 & +25000 & +5000 & -110704 & 0 & 0 & 0 \\
Loans & 0 & -52194.4 & -1298 & +53492.5 & 0 & 0 & 0 \\
Cons. Goods & 0 & +2997.4 & 0 & 0 & 0 & 0 & +2997.4 \\
Cap. Goods & 0 & +53863.6 & +500 & 0 & 0 & 0 & +54363.6 \\
Bonds & 0 & 0 & 0 & +38273.5 & -66838.1 & +28564.6 & 0 \\
Reserves & 0 & 0 & 0 & +28564.6 & 0 & -28564.6 & 0 \\
Advances & 0 & 0 & 0 & 0 & 0 & 0 & 0 \\
\hline Net Worth & +80704.1 & +29666.6 & +4202 & +9626.4 & -66838.1 & 0 & +57361 \\
\hline
\end{tabular}

Table 1: Aggregate Balance Sheet (Initial Situation)

\begin{tabular}{|c|c|c|c|c|c|c|c|c|c|c|c|}
\hline & \multirow[t]{2}{*}{ Households } & \multicolumn{2}{|c|}{ Cons. Firms } & \multicolumn{2}{|c|}{ Cap. Firms } & \multicolumn{2}{|c|}{ Banks } & \multirow[t]{2}{*}{ Govt. } & \multicolumn{2}{|c|}{ Central Bank } & \multirow[t]{2}{*}{$\Sigma$} \\
\hline & & $\mathrm{CA}$ & $\mathrm{KA}$ & $\mathrm{CA}$ & $\mathrm{KA}$ & $\mathrm{CA}$ & $\mathrm{KA}$ & & $\mathrm{CA}$ & $\mathrm{KA}$ & \\
\hline Consumption & -32971.4 & +32971.4 & 0 & 0 & 0 & 0 & 0 & 0 & 0 & 0 & 0 \\
\hline Wages & +36800 & -25000 & 0 & -5000 & 0 & 0 & 0 & -6800 & 0 & 0 & 0 \\
\hline Dole & +1280 & 0 & 0 & 0 & 0 & 0 & 0 & -1280 & 0 & 0 & 0 \\
\hline CG on inventories & 0 & +22.3 & -22.3 & +3.7 & -3.7 & 0 & 0 & 0 & 0 & 0 & 0 \\
\hline Investments & 0 & 0 & -5375 & +5375 & 0 & 0 & 0 & 0 & 0 & 0 & 0 \\
\hline Capital Amortization & 0 & -4974 & +4974 & 0 & 0 & 0 & 0 & 0 & 0 & 0 & 0 \\
\hline Taxes & -7084.7 & -484.8 & 0 & -68.7 & 0 & -39.3 & 0 & +7677.4 & 0 & 0 & 0 \\
\hline Dep. Interest & +200.3 & +62 & 0 & +12.4 & 0 & -274.7 & 0 & 0 & 0 & 0 & 0 \\
\hline Bonds Interest & 0 & 0 & 0 & 0 & 0 & +95 & 0 & -165.9 & +70.9 & 0 & 0 \\
\hline Loans Interest & 0 & -388.5 & 0 & -9.7 & 0 & +398.2 & 0 & 0 & 0 & 0 & 0 \\
\hline Advances Interest & 0 & 0 & 0 & 0 & 0 & 0 & 0 & 0 & 0 & 0 & 0 \\
\hline Profits & +2367.6 & -2208.4 & +220.8 & -312.8 & +31.3 & -179.1 & +71.7 & 0 & 0 & 0 & 0 \\
\hline CB profits & 0 & 0 & 0 & 0 & 0 & 0 & 0 & +70.9 & -70.9 & 0 & 0 \\
\hline$\Delta$ Deposits & -600.8 & 0 & -186.1 & 0 & -37.2 & 0 & +824.1 & 0 & 0 & 0 & 0 \\
\hline$\Delta$ Advances & 0 & 0 & 0 & 0 & 0 & 0 & 0 & 0 & 0 & 0 & 0 \\
\hline$\Delta$ Reserves & 0 & 0 & 0 & 0 & 0 & 0 & -212.6 & 0 & 0 & +212.6 & 0 \\
\hline$\Delta$ Gov. Bonds & 0 & 0 & 0 & 0 & 0 & 0 & -284.9 & +497.6 & 0 & -212.6 & 0 \\
\hline$\Delta$ Loans & 0 & 0 & +388.5 & 0 & +9.7 & 0 & -398.2 & 0 & 0 & 0 & 0 \\
\hline$\Delta$ Total & 0 & 0 & 0 & 0 & 0 & 0 & 0 & 0 & 0 & 0 & 0 \\
\hline
\end{tabular}

Table 2: Aggregate Transaction Flow Matrix (Initial Situation) 
Table 3: Parameters

\begin{tabular}{|c|c|c|c|}
\hline Symbol & Description & Baseline & Sensitivity \\
\hline$g_{S S}:$ pre-SS & Nominal rate of growth in the SS & 0.0075 & same \\
\hline size $_{\Phi_{H}}$ : pre-SS & Number of households & 8000 & same \\
\hline size $_{\Phi_{C}}$ : pre-SS & Number of consumption firms & 100 & same \\
\hline size $_{\Phi_{K}}:$ pre-SS & Number of capital firms & 20 & same \\
\hline size $_{\Phi_{B}}$ : pre-SS & Number of banks & 10 & same \\
\hline$N_{g t}:$ SS-given & Number of public servants (constant) & 1360 & same \\
\hline$N_{c 0}:$ pre-SS & Consumption firms' initial workers & 4000 & same \\
\hline$N_{k 0}:$ pre-SS & Capital firms' initial workers & 1000 & same \\
\hline$u_{0}:$ pre-SS & Initial unemployment & 0.08 & same \\
\hline$\mu_{N}:$ SS-given & Productivity of labor in $\mathrm{K}$ sector & 2 & same \\
\hline $\begin{array}{l}\left\{\mu_{k}, l_{k}\right\}: \text { pre-SS and } \\
\text { SS-given }\end{array}$ & Productivity and capital/labor ratios of $\mathrm{K}$ & $\{1,6.4\}$ & same \\
\hline$\chi_{c}=\chi_{k}:$ free & $\begin{array}{l}\text { Number of potential partners on } \mathrm{C} \text { and } \mathrm{K} \\
\text { goods mkts }\end{array}$ & 5 & same \\
\hline$\chi_{d}=\chi_{l}:$ free & $\begin{array}{l}\text { Number of potential partners on deposit-credit } \\
\text { mkts }\end{array}$ & 3 & same \\
\hline$\chi_{n}:$ free & $\begin{array}{l}\text { Number of potential partners on labor mkt (for } \\
\text { each vacant job) }\end{array}$ & 10 & same \\
\hline$\epsilon^{d}=\epsilon^{l}:$ free & Intensity of choice in deposit-credit mkts & 4.62098 & same \\
\hline$\epsilon^{c}=\epsilon^{k}:$ free & Intensity of choice in $\mathrm{C}$ and $\mathrm{K}$ goods mkts & 3.46574 & same \\
\hline$\nu:$ pre-SS & Firms' inventories target share & 0.1 & same \\
\hline$\lambda:$ free & Adaptive expectations parameter & 0.25 & same \\
\hline$\vartheta:$ free & Labor turnover ratio & 0.05 & same \\
\hline$\mu_{c 0}:$ pre-SS & Initial mark-up on ULC for $\mathrm{C}$ firms & 0.318857 & same \\
\hline$\mu_{k 0}:$ pre-SS & Initial mark-up on ULC for K firms & 0.075 & same \\
\hline$\left(\mu_{F N}, \sigma_{F N}^{2}\right):$ free & Folded Normal Distribution parameters & $(1,0.0094)$ & same \\
\hline$\tau_{\pi}=\tau_{i}:$ pre-SS & Profit and Income tax rates & 0.18 & same \\
\hline$\eta:$ pre-SS & Loans duration & 20 & same \\
\hline$\kappa:$ pre-SS & Capital goods duration & 20 & same \\
\hline $\bar{r}$ : SS-given & Target profit rate (Investment function) & 0.04345 & same \\
\hline $\bar{u}$ : SS-given & $\begin{array}{l}\text { Target capacity utilization (Investment func- } \\
\text { tion) }\end{array}$ & 0.8 & same \\
\hline$\gamma_{1}:$ free & Profit rate weight (Investment function) & 0.01 & $0.000: 0.005: 0.040$ \\
\hline$\gamma_{2}:$ free & $\begin{array}{l}\text { Capacity utilization rate weight (Investment } \\
\text { function) }\end{array}$ & 0.02 & $0.000: 0.005: 0.040$ \\
\hline$\sigma:$ pre-SS & Firms' precautionary deposits as share of WB & 1 & $0.5: 0.1: 1.5$ \\
\hline$\rho_{c}=\rho_{k}:$ pre-SS & Firms' profits' share distributed as dividends & 0.9 & same \\
\hline$\rho_{b}:$ pre-SS: & Banks' profit share distributed as dividends & 0.6 & same \\
\hline$i_{b 0}^{l}:$ pre-SS & Initial interest rate on loans & 0.0075 & same \\
\hline$i_{b 0}^{d}:$ pre-SS & Initial interest rate on deposits & 0.0025 & same \\
\hline$C R_{0}^{T}$ : SS-given & Initial banks' target capital ratio & 0.17996 & same \\
\hline$L R_{0}^{\underline{T}}:$ SS-given & Initial banks' target liquidity ratio & 0.258026342 & same \\
\hline$\varsigma_{c}:$ free & Banks' risk aversion towards C firms & 3.92245 & $1.0: 1.0: 10.0$ \\
\hline$\varsigma_{k}:$ free & Banks' risk aversion towards $\mathrm{K}$ firms & 21.51335 & $5.0: 5.0: 40.0$ \\
\hline $\bar{i}_{c b}^{a}:$ pre-SS & $\mathrm{CB}$ interest rates on advances & 0.005 & same \\
\hline$\iota:$ free & Haircut on defaulted firms' capital value & 0.5 & same \\
\hline$w_{n 0}:$ pre-SS & Initial wages & 5 & same \\
\hline$\omega:$ pre-SS & Dole (share of average wages) & 0.4 & same \\
\hline$v:$ free & $\begin{array}{l}\text { Unemployment threshold in wage revision } \\
\text { function }\end{array}$ & 0.08 & same \\
\hline$\alpha_{1}$ : SS-given & Propensity to consume out of income & 0.38581 & same \\
\hline$\alpha_{2}:$ pre-SS & Propensity to consume out of wealth & 0.25 & same \\
\hline $\bar{i}^{b}:$ pre-SS & Bonds interest rate & 0.0025 & same \\
\hline $\bar{p}^{b}:$ pre-SS & Bonds price & 1 & same \\
\hline
\end{tabular}

